Technological University Dublin

ARROW@TU Dublin

\title{
Efficacy and mechanistic insights into endocrine disruptor degradation using atmospheric air plasma
}

\author{
Chaitanya Sarangapani \\ Technological University Dublin, chaitanyakrishna.sarangapani@tudublin.ie \\ M. Danaher \\ Teagasc Food Research Centre \\ Brijesh Tiwari \\ Teagasc Food Research Centre
}

See next page for additional authors

Follow this and additional works at: https://arrow.tudublin.ie/schfsehart

Part of the Chemical Engineering Commons, and the Civil and Environmental Engineering Commons

\section{Recommended Citation}

C. Sarangapani, M. Danaher, Brijesh Tiwari, Peng Lu, Paula Bourke, P.J. Cullen, Efficacy and mechanistic insights into endocrine disruptor degradation using atmospheric air plasma, Chemical Engineering Journal, Volume 326, 2017, Pages 700-714, ISSN 1385-8947, DOI: 10.1016/j.cej.2017.05.178.

This Article is brought to you for free and open access by the School of Food Science and Environmental Health at ARROW@TU Dublin. It has been accepted for inclusion in Articles by an authorized administrator of ARROW@TU Dublin. For more information, please contact arrow.admin@tudublin.ie, aisling.coyne@tudublin.ie, gerard.connolly@tudublin.ie.

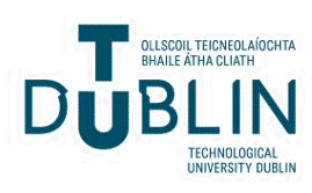


Authors

Chaitanya Sarangapani, M. Danaher, Brijesh Tiwari, Peng Lu, Paula Bourke, and Patrick J. Cullen

This article is available at ARROW@TU Dublin: https://arrow.tudublin.ie/schfsehart/468 


\title{
Efficacy and mechanistic insights into endocrine disruptor degradation using atmospheric air plasma
}

\author{
C. Sarangapani ${ }^{\mathrm{a}}$, M. Danaher ${ }^{\mathrm{b}}$, Brijesh Tiwari ${ }^{\mathrm{b}}$, Peng Lu ${ }^{\mathrm{a}}$, Paula Bourke ${ }^{\mathrm{a}}$, P.J. Cullen ${ }^{\mathrm{c}, \mathrm{d}, *}$ \\ ${ }^{a}$ BioPlasma Research Group, Dublin Institute of Technology, Dublin 1, Ireland \\ ${ }^{\mathrm{b}}$ Teagasc Food Research Centre, Ashtown, Dublin 15, Ireland \\ ' School of Chemical Engineering, University of New South Wales, Sydney, Australia \\ ${ }^{\mathrm{d}}$ Department of Chemical and Environmental Engineering, University of Nottingham, UK
}

\section{H I G H L I G H T S}

- Atmospheric air plasma effectively degrades endocrine disruptors in a model dairy effluent.

- The plasma was created at the gas-liquid interface and is an abundant source of reactive oxygen and nitrogen species.

- The degradation of endocrine disruptors followed first order kinetics.

- A degradation mechanism for the three endocrine disruptors is proposed.

\section{A R T I C L E I N F O}

\section{Article history:}

Received 28 February 2017

Received in revised form 30 May 2017

Accepted 30 May 2017

Available online 10 July 2017

\section{Keywords:}

Atmospheric air plasma

Endocrine disruptors

Degradation

\begin{abstract}
A B S T R A C T
Endocrine disruptors are a class of contaminants found in water and process effluents at low concentrations. They are of concern due to their high estrogenic potency. Their presence in the environment has led to the search for effective techniques for their removal in wastewater. For this purpose, an atmospheric air plasma reactor was employed for the study of the degradation of three endocrine disruptor chemicals (EDC) namely; bisphenol A (BPA), estrone (E1) and 17 $\beta$-estradiol (E2) within a model dairy effluent. Identification of the plasma induced active species both in the gas and liquid phases were performed. Also studied was the influence of an inhibitor, namely tertiary butanol, on the degradation of the EDCs. The results demonstrate that air plasma could successfully degrade the tested EDCs, achieving efficacies of $93 \%\left(k=0.189 \mathrm{~min}^{-1}\right)$ for BPA, 83\% $\left(k=0.132 \mathrm{~min}^{-1}\right)$ for E1 and $86 \%\left(k=0.149 \mathrm{~min}^{-1}\right)$ for E2, with the process following first order kinetics. The removal efficacy was reduced in the presence of a radical scavenger confirming the key role of oxygen radicals such as ${ }^{\circ} \mathrm{OH}$ in the degradation process. The intermediate and final products generated in the degradation process were identified using UHPLC-MS and LC-MS. Based on the intermediates identified a proposed degradation pathway is presented.
\end{abstract}

(c) 2017 Elsevier B.V. All rights reserved.

\section{Introduction}

Endocrine disrupting compounds (EDCs) are organic chemicals which are either excreted endogenously from humans and animals or are derived from uses in clinical practices [1]. An EDC is defined as an exogenous agent that alters the function(s) of the endocrine system, leading to adverse health effects in organisms [2]. Endocrine disruptors vary widely in their structure and have numerous uses in everyday items including; electrical appliances, clothing, furniture and cosmetics. They can also include pesticides (e.g.,

\footnotetext{
* Corresponding author at: Department of Chemical and Environmental Engineering, University of Nottingham, NG7 2RD, UK.

E-mail address: patrick.cullen@nottingham.ac.uk (P.J. Cullen).
}

DDE, dicofol), plastics (bisphenol A, phthalates), food preservatives (UV-filters), hormonal agents and phytoestrogens. The presence of EDCs has been widely detected in surface waters, process effluents and sewage sludge treatment plants (STP). Hartmann et al. [3] has reported that the main source of animal-derived estrogens (60$70 \%$ ) in the human diet is milk and dairy products. Estrogen content is mostly distributed in the fat phase because of its solubility. Food processing operations do not typically affect the hormone patterns. Animal fecal and urinary excretions may also result in the occurrence of estrogens in dairy effluents [4]. Recently, free and conjugated forms of estrogens including $17 \beta$-estradiol and estrone have been detected in milk and milk products [3]. Inappropriate disposal, leaching and poor removal by conventional wastewater treatment processes (WWTP) are identified areas of 
concern. Various studies have reported on the occurrence of these emerging contaminants, including those from dairy and meat process effluents $[5,6]$.

When effluents containing chemicals are used for agricultural crops they can be transported to surface or ground waters. Colbron et al. [7] reported that EDCs are associated with reproductive and sexual abnormalities in animals and wildlife. The effects of EDCs include; fish feminization, changes in reproduction and behavior, decrease in number of spermatozoids, increase in breast cancer rates and an increase of certain anomalies in the human reproductive system [8-10]. With particular concern to human health, it is paramount that these chemicals are effectively treated before entering drinking water supplies, however for such hydrophobic contaminants, conventional treatment may be ineffective. Biological processes have been used for their treatment however, such chemicals have been found to be resistant and/or toxic to microbes and consequently they cannot be readily treated by biological processes $[11,10]$. Consequently, such treatment processes may not reach the required regulatory limits for these contaminants. It is reported that the regulatory limits for all EDCs is $<0.0001 \mathrm{mg} / \mathrm{L}$ [12]. Chlorination of EDCs and its chlorinated products have been reported to elicit estrogenic activity [13]. Moreover, chlorination leads to the production of disinfection by-products (DBPs) that may be residually present in the treated effluent and pose a potential risk to consumers. Several authors had reported on the removal of these chemicals by advanced oxidation process (AOPs) such as ozonation [14], $\mathrm{UV} / \mathrm{H} 2 \mathrm{O} 2$ [15] and TiO2 photocatalysis [16]. However, in the case of the later, an additional step for the removal of the reagents used and incomplete mineralization might increase the operational costs. As a result, there is a need to find a sustainable, effective and economical process for degrading and removing EDCs from effluents.

Recently, dielectric barrier discharge non-thermal plasma (DBD-NTP) oxidation has emerged as a promising technology for eliminating organic micropollutants with high removal rates and environmental compatibility [17]. Plasma is a partially or wholly ionized state which consists of positively and negatively charged ions, free electrons, free radicals and intermediate highly reactive species, atoms, molecules and UV photons $[18,19]$. Plasma can be generated either in the gas or liquid phase simultaneously [20]. The electron impact dissociation of oxygen and water molecules leads to generation of numerous active species such as $\mathrm{O}, \cdot \mathrm{OH}, \mathrm{N}$, $\mathrm{HO}_{2}, \mathrm{~N}_{2}^{*}, \mathrm{~N}^{*}, \mathrm{OH}^{-}, \mathrm{O}_{2}^{-}, \mathrm{O}^{-}, \mathrm{O}_{2}^{+}, \mathrm{N}_{2}^{+}, \mathrm{N}^{+}, \mathrm{O}^{+}$, and $\mathrm{O}_{3}, \mathrm{H}_{2} \mathrm{O}_{2}$ following subsequent chemical reactions [21,22]. These species react with chemicals causing oxidation. Moreover, pollutant degradation could be initiated by UV light or shock waves. Recently, several authors have reported on the potential of DBD plasma technology for the removal of toxic chemicals from wastewaters such as pollutant dyes [23], pesticides [24,25], mycotoxins [26], volatile organic compounds [27,28] and antibiotics [29]. Recently Gao et al. [30], reported on the degradation of estrogenic endocrine disruptors by DBD plasma technology. A DBD plasma source combined with a $\mathrm{Pt}-\mathrm{TiO}_{2}$ photocatalyst was developed by Chen et al. [31] which demonstrated effective degradation of $17 \beta$-estradiol. The application of DBD plasma to the treatment of bisphenol A and tributyltin was studied by Hijosa-Valsero et al. [32], demonstrating that plasma can be an alternative AOP for the removal of persistent and toxic pollutants from water and wastewater. Abdelmalek and co-authors [33] used a gliding arc discharge plasma reactor to study the degradation of the endocrine disruptor bisphenol A with ferrous ions. They found that both hydroxyl radicals and hydrogen peroxide are responsible for the degradation effect and the addition of ferrous ions (II) allowed for greater mineralization via the production of additional hydroxyl radicals, according to the Fenton reaction.
The selection of an oxidation process may depend upon many factors such as the degree of degradation, the by-products formed in the process, the total cost, safety and reliability of the process [34]. Most studies to date on pollutant degradation using plasma have been carried out in the absence of competing organic matter. In this study, a novel high voltage and low-frequency DBD prototype reactor was employed which utilized atmospheric air as the inducer gas for the degradation of EDCs in a model dairy effluent. Furthermore, identification of degraded products and possible mechanisms of EDC degradation in the presence of dairy effluent is also studied.

\section{Materials and methods}

\subsection{Materials}

Analytical grade standards of Bisphenol A (BPA), Estrone (E1) and $17 \beta$-Estradiol (E2) of purity (>96\%), HPLC grade methanol, acetonitrile, ethyl acetate, ammonium hydroxide solution (32\%) puriss p.a. $(\mathrm{NH} 4 \mathrm{OH})$, acetic acid $(\mathrm{AcOH})$, formic acid $(\mathrm{HCOOH})$, sodium acetate (NaOAc), ammonium formate, tert-butyl alcohol(TBA) and LC-MS grade water were obtained from Sigma-Aldrich (Ireland).

\subsection{Sample preparation}

A model dairy effluent was prepared by dissolving $4 \mathrm{~g}$ of skim milk powder, $0.4 \mathrm{~g}$ of milk fat and $0.01 \%$ of $\mathrm{NaOH}$ per liter of distilled water [35]. The model effluent was used to overcome inherent variability in commercial effluent composition. Large particulate matter was removed by filtering the model effluent through a Whatman (UK) filter paper and a $0.45 \mu \mathrm{m}$ membrane (Millipore). Each endocrine disruptor (BPA, E1 and E2) was dissolved in acetonitrile to obtain a standard stock solution with the concentration $100 \mathrm{mg} / \mathrm{L}$. The prepared stock solution was diluted and spiked with the filtered model effluent to obtain a concentration of $2 \mathrm{mg} / \mathrm{L}$.

\subsection{Experimental procedure}

\subsubsection{Atmospheric air plasma treatment}

The experimental set-up employed for this work is shown in Fig. 1. The experimental apparatus consisted of two aluminium plate electrodes of circular geometry (outer diameter $=158 \mathrm{~mm}$ ) which were covered with dielectric materials of $2 \mathrm{~mm}$ thickness for ground electrode and $10 \mathrm{~mm}$ thick acrylic sheet for the high voltage electrode. For each experiment, $20 \mathrm{~mL}$ of dairy effluent spiked with EDC's (at an initial concentration of $2 \mathrm{mg} / \mathrm{L}$ ) was added to petri dish and placed within a polypropylene (PP) container of dimensions $310 \mathrm{~mm} \times 230 \mathrm{~mm} \times 22 \mathrm{~mm}$ which acts as a closed reactor and as an additional dielectric barrier. This container was further sealed inside a high barrier Cryovac BB3050 film in order to prevent loss of reactive species generated during plasma treatment. The voltage was delivered through a step-up transformer (Phenix Technologies, Inc., USA) whose primary winding received an input at $230 \mathrm{~V}, 50 \mathrm{~Hz}$ and delivered a high voltage output in the range $0-120 \mathrm{kV}_{\mathrm{RMS}}$. Plasma treatment was performed at varying voltage $(60-80 \mathrm{kV})$ and treatment durations $(0-15 \mathrm{~min})$. Treatment of samples was carried out in duplicate at ambient temperature $\left(16-18^{\circ} \mathrm{C}\right)$. After processing, containers were stored at room temperature of $16-18^{\circ} \mathrm{C}$ for $24 \mathrm{~h}$ to ensure that the generated and contained reactive species reacted with the samples. Ozone concentrations were measured using short-term ozone detection tubes obtained from Gastec (Product No. 18M, Gastec, Japan). These tubes contain a reagent which changes color after coming into contact with the specified gas and are calibrated for 


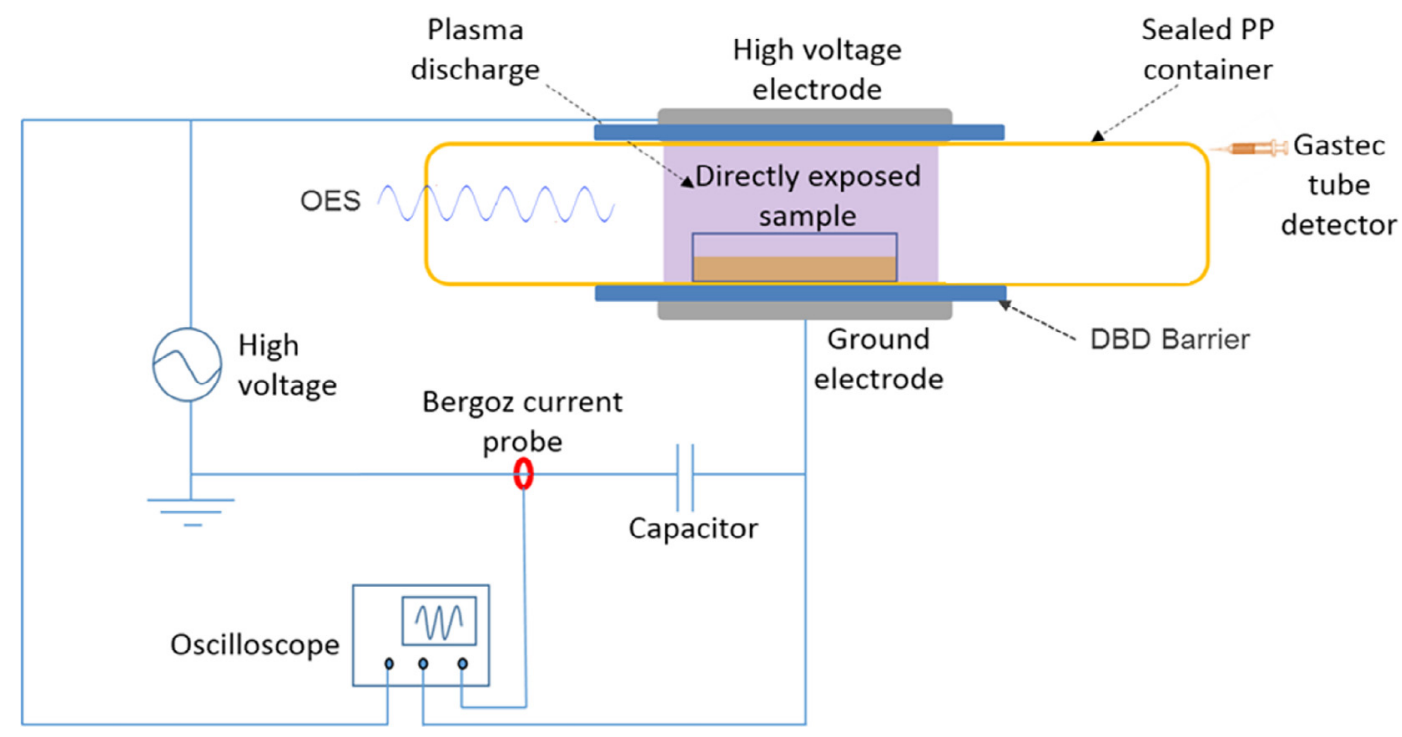

Fig. 1. Schematic of the experimental setup with electrical and optical diagnostics.

specific sampling volumes. Ozone concentrations were measured immediately following treatment. The emission spectra of the discharge were acquired with a computer controlled Ocean Optics spectrometer (HR2000+), to which the light from the plasma is coupled via an optical fibre [36]. Further details regarding gas measurement methodology for ozone, electrical characterization and the optical emission spectroscopy experiments can be found elsewhere [24]. The conductivity of the effluent was measured using a conductivity meter (model CON-BTA, Vernier Software \& Technology Inc.) at ambient temperature $\left(16^{\circ} \mathrm{C}\right)$ and turbidity was measured by using a Hach $2100 \mathrm{P}$, ISO USA turbidity meter. The $\mathrm{pH}$ of all the samples were measured after $24 \mathrm{~h}$ storage using a calibrated glass electrode ORION pH meter (model 420A, Thermo Fisher Scientific Inc.) at ambient temperature $\left(16^{\circ} \mathrm{C}\right)$. Total organic carbon (TOC) of the dairy effluent was measured using a digestion unit DRB 200, Hach, USA and double beam UV-visible spectrophotometer Hach, DR 2400, USA.

\subsection{Sample extraction}

The plasma treated model effluents were firstly extracted by solid-phase extraction (SPE). The extraction was carried out using a solid phase cartridge (Supelclean ${ }^{\mathrm{TM}}-\mathrm{ENVI}^{\mathrm{TM}}-18$ ), previously preconditioned by flushing with acetonitrile followed by methanol $(3 \times 3 \mathrm{~mL})$. In succession, the cartridges were washed with water $(3 \times \mathrm{mL})$ and then the sample was passed through the cartridges at a flow rate of $10 \mathrm{~mL} / \mathrm{min}$ with the aid of a vacuum. These cartridges were dried and elution was performed with methanol $(3 \times 3 \mathrm{~mL})$. The methanol extracts were evaporated to dryness under nitrogen stream and re-suspended in $1.5 \mathrm{~mL}$ of acetonitrile.

\subsection{Analytical methods}

Standard curves for the EDC's were established using standard solutions ranging between $0.05 \mathrm{mg} / \mathrm{L}$ and $5 \mathrm{mg} / \mathrm{L}$ using acetonitrile as solvent. The linear correlation coefficients $\left(\mathrm{r}^{2}\right)$ were $0.997,0.998$ and 0.997 for BPA, E1 and E2 respectively. The quantification of EDCs was determined using a HPLC system which consisted of a Waters 600 Satellite connected to a Waters 996 PDA detector and Waters auto-sampler (Waters, Ireland). Separation was carried out on a Phenomenex Gemini-Nx C18 column (Phenomenex, U.K.), $5 \mu \mathrm{m}$ particle size $(250 \mathrm{~mm} \times 4.6 \mathrm{~mm})$. The mobile phase consisted of $70 \%$ acetonitrile and $30 \%$ water, and the flow rate was set at $0.6 \mathrm{~mL} / \mathrm{min}$.
The detector wavelength was set at 210-400 nm. Chromatographic data was collected and processed using Empower2 software (Waters, Ireland). The SPE recoveries obtained in the present study were found to be $97 \%$ for BPA, $92 \%$ for E1 and 94\% E2 respectively.

The degradants were analyzed using an Acquity UHPLC coupled to a Quattro Premier XE triple quadrupole instrument operating in electrospray ionization (ESI) mode (all from Waters, Milford, MA, USA). Separation was carried out in an Acquity BEH $\mathrm{C}_{8}$ analytical column $(2.1 \times 50 \mathrm{~mm}$, particle size $1.7 \mu \mathrm{m})$ maintained at $30^{\circ} \mathrm{C}$. A binary gradient system was used to separate analytes comprising of mobile phase A, $5 \mathrm{mM} 0.24 \mathrm{mM}$ ammonium formate in $\mathrm{MeOH} /$ $\mathrm{H}_{2} \mathrm{O}(80: 20, \mathrm{v} / \mathrm{v})$ and mobile phase $\mathrm{B}, 5 \mathrm{mM}$ of ammonium formate in $\mathrm{MeOH}$. The gradient profile was linear from $80 \%$ A to $30 \%$ A over $5 \mathrm{~min}$ and $0 \% \mathrm{~A}$ at $6.5 \mathrm{~min}$ then $2 \mathrm{~min}$ at $0 \% \mathrm{~A}$ followed by $2 \mathrm{~min}$ for re-equilibration at $80 \% \mathrm{~A}$. The UHPLC-MS system was controlled by MassLynx $^{\mathrm{TM}}$ software and data was processed using TargetLyn ${ }^{\mathrm{TM}}$ software (all from Waters). A Full scan mode was used to acquire MS spectra of the intermediates with a scan range of $m / z 80$ 500. Transformation products were also identified using LC-MS. The organic acids in the dairy effluent were quantified by an ion chromatograph (ICS 3000, Dionex, USA) at $30^{\circ} \mathrm{C}$.

\subsection{Determination of nitrite, nitrate and hydrogen peroxide}

Nitrite concentrations in the effluent were quantified by employing the Griess reagent ( $\mathrm{N}$-(1-naphthyl) ethylenediamine dihydrochloride) spectrophotometric method [37]. This was accomplished by the addition of $100 \mu$ sample, trichloroacetic acid and Griess reagent. The reaction mixture was incubated at $37^{\circ} \mathrm{C}$ for $30 \mathrm{~min}$, after which the absorbance was determined at $548 \mathrm{~nm}$ using a UV-visible spectrophotometer (Shimadzu UV-1800, Shimadzu Scientific Instruments Kyoto, Japan). A calibration curve was prepared using a standard solution of sodium nitrite. Nitrate concentrations were determined according to the procedure of $\mathrm{Lu}$ et al. [38]. Hydrogen peroxide concentrations were determined according to the procedure of Bohem et al. [39].

\subsection{Degradation kinetic modelling study and data analysis}

The removal efficiencies $(\eta)$ of EDC's were calculated according to the following equation:

$\eta=\frac{C_{0}-C}{C_{0}} \times 100$ 
where $\eta$ is removal efficiency of each EDC, $C$ is the concentration of EDCs at time ' $t$ ' and $C_{0}$ the initial concentration of the EDC. Plasma degradation of EDCs in aqueous media followed first order kinetics $[25,40]$ as described in the following equation

$C=C_{0} \exp (-k t)$

where $\boldsymbol{k}$ is the degradation rate constant $\left(\mathrm{min}^{-1}\right)$ of the reaction and $\boldsymbol{t}$ is the treatment time ( $\mathrm{min}$ ) and energy yield was calculated according to the procedure of Jiang et al. [41].

\section{Results and discussion}

\subsection{Current-Voltage characteristic of plasma source}

Fig. 2 shows the typical current-voltage waveform for the discharges within the reactor at the applied voltages. It can be observed that the applied voltage was sinusoidal and total current is the combination of displacement current and several current pulses associated with filamentary micro-discharges. A stable discharge was found at the high voltages employed even at the large discharge gap of $2.2 \mathrm{~cm}$. The dielectric used acts a charge trapping agent and also prevents arcing [42]. Further details regarding the electrical characteristics of the discharge using capacitancevoltage Lissajous patterns can be found in a previous publication [43].

\subsection{Evaluation of removal efficiency and degradation kinetics}

The endocrine disruptors, namely estrone (E1), 17 $\beta$-estradiol (E2) and bisphenol A (BPA) were identified using chromatographic retention time data. The EDCs were shown to degrade significantly by $>25 \%$ and $>42 \%$ following plasma treatment times of 5 and 15 min respectively, for all applied voltages (Fig. 3.). A significant increase in removal efficiencies was also achieved with increase in applied voltage from $60 \mathrm{kV}$ to $80 \mathrm{kV}$. The maximum removal efficiencies achieved were $83.57 \pm 0.45 \%, 86.52 \pm 0.75 \%$ and
$93.90 \pm 0.92 \%$ for $\mathrm{E} 1, \mathrm{E} 2$ and BPA respectively, after $80 \mathrm{kV}$ for 15 min of plasma treatment. Similar results were observed for the degradation of methylene blue and pesticides by nonthermal plasma $[23,25]$. In order to confirm the effect of the plasma process parameters and systematic analysis for removal of contaminants, the degradation was modelled using a first order kinetic model Fig. 4. It is evident from Table 1 that the first order kinetic model is in reasonable agreement with the experimental data, with correlation coefficients $>0.90$. Increase in applied voltage from $60 \mathrm{kV}$ to $80 \mathrm{kV}$, resulted in an increase in the rate constant values (k) from 0.045 to $0.189 \mathrm{~min}^{-1}$ for all three EDCs. Atmospheric air plasma are known to produce a variety of excited and active species, such as $\mathrm{O}^{\cdot}, \mathrm{OH}, \mathrm{N}, \mathrm{HO}_{2}, \mathrm{~N}_{2}^{*}, \mathrm{~N}^{*}, \mathrm{OH}^{-}, \mathrm{O}_{2}^{-}, \mathrm{O}^{-}, \mathrm{O}_{2}^{+}, \mathrm{N}_{2}^{+}, \mathrm{N}^{+}$, and $\mathrm{O}^{+}[42]$ in the gas phase or at the liquid interface, which can dissolve into solutions leading to contaminant oxidation. The active species generated not only react with the target contaminant but also with the degraded products. During plasma treatment EDCs are oxidized through an attack by the active species such as the ozone molecule, the hydroxyl radical and hydrogen peroxide. Ozone reacts selectively with certain functional groups, whereas an indiscriminate reaction occurs with the hydroxyl radical [44]. The degradation of a contaminant by plasma depends on many factors such as sample concentration, sample volume, electrode gap, sample chemistry, reactor type, discharge gas and sample viscosity. The electrode gap is an important plasma process parameter for DBDs. In the present study, a stable discharge was achieved at the very high voltages employed facilitating a large discharge gap of $2.2 \mathrm{~cm}$. The physical processes occurring during air breakdown and the micro-discharges formed in the gap govern the resultant chemistry [45]. This novel plasma design of high voltage, low frequency and large gap atmospheric air DBD has demonstrated rapid treatment efficacies for a range of processes [12,14-16].

The chemical structure of the contaminant is the dominant factor for the target's persistence as it influences the chemical stability during the degradation reaction [46]. The degradation behavior of E1, E2 are found to be similar due to their comparable chemical structure, whereas a slight difference was observed for BPA. The
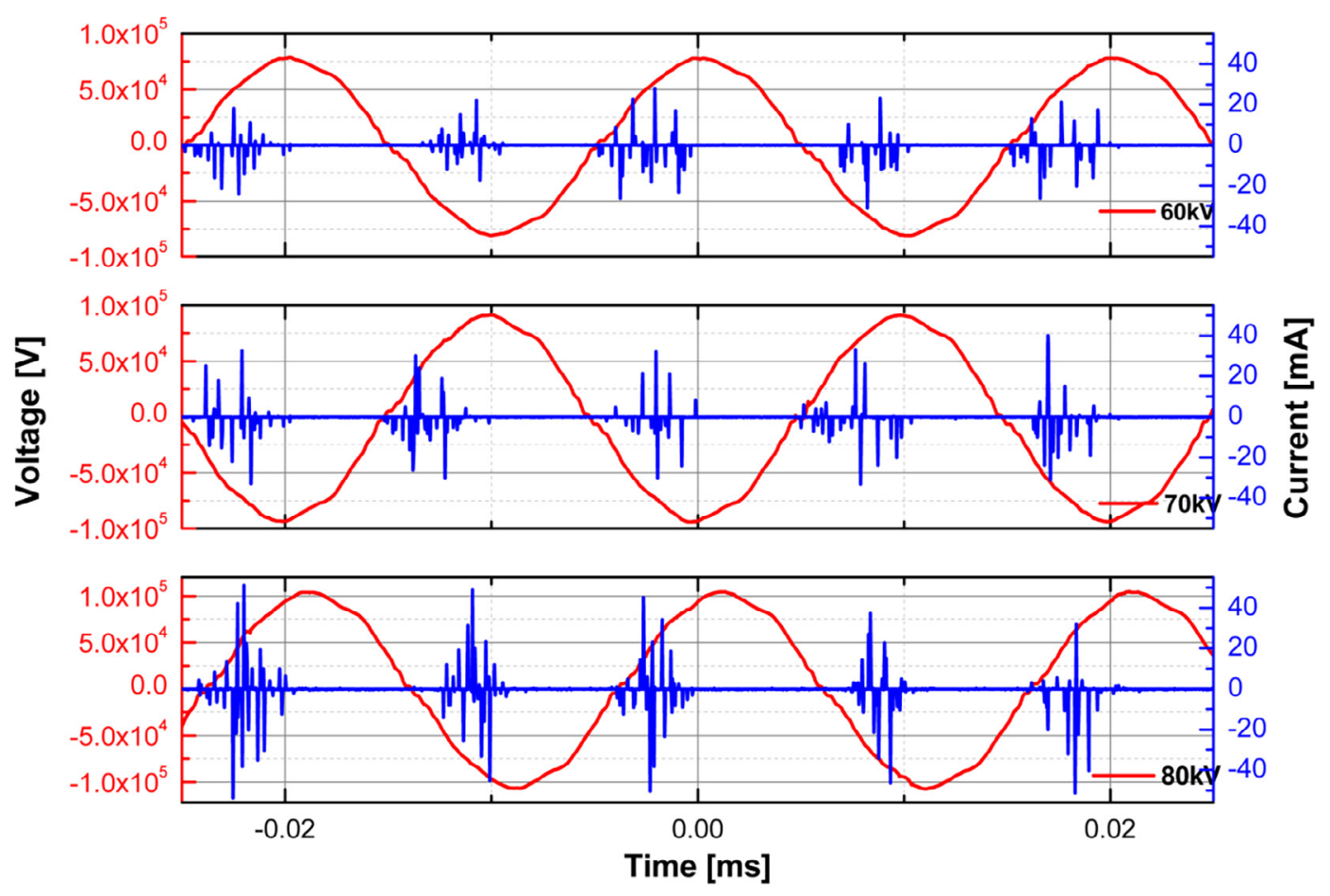

Fig. 2. Representative current-voltage characteristics of the discharge. 

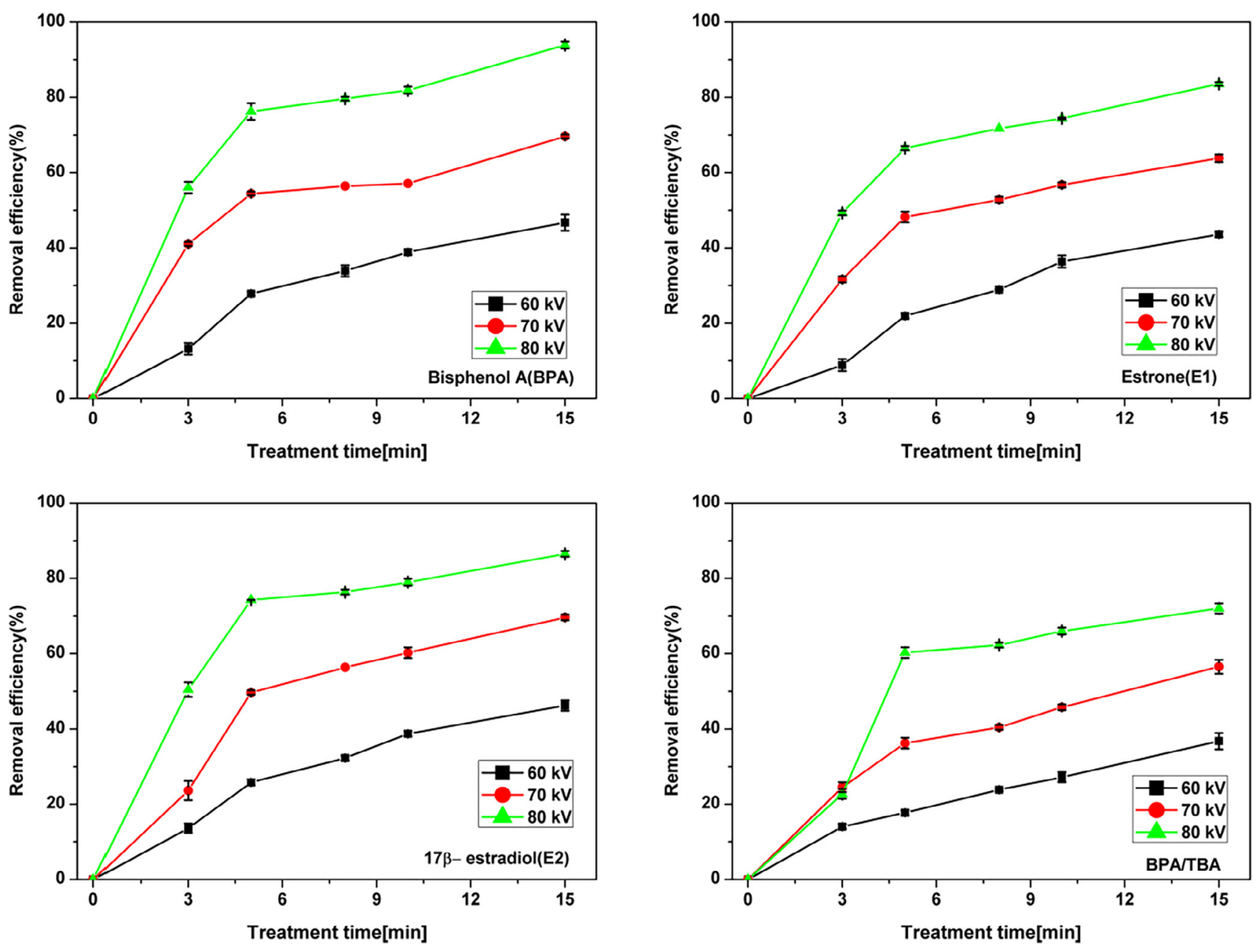

Fig. 3. Percentage degradation of endocrine disruptors in model effluent. BPA/TBA refers to degradation in presence of radical scavenger tertiary butanol alcohol.

high degradation rates obtained are due to the effective generation of large quantities of active species during the discharge coupled with the retention of the species within the confines of the reactor post discharge. Similar reports were observed for ozonation of phenolic pharmaceutical compounds by Boyd et al. [47]. The plasma active species specifically attack the high electron density carbon $(\mathrm{C}=\mathrm{C})$ double bond, activated aromatic acids and non-protonated amines. This is due to the donation of an electron by the hydroxyl group to the benzene ring which activates the aromatic system and facilitates oxidative attack by ozone [47]. In our study, a closed reactor setup was employed by placing the samples in the polypropylene (PP) container. These reactors were stored for $24 \mathrm{~h}$ to ensure that the generated and contained reactive species reacted with the samples, post plasma treatment. The plasma species also diffuse to regions outside of the discharge zone within the reactor. The degradation of EDCs was found to be greater inside the discharge zone, which is due to the presence of all the reactive species (electrons, ions, free radicals, etc.) when compared to the remote regions where meta-stables are only found. Nevertheless, EDC degradation was found to occur with exposure to either a direct discharge or the retained afterglow [36].

A brief comparison of the different methods of EDC removal is summarized in Table 2. It is observed that $70 \%$ of E1 can be removed by chlorination for a contact time of $15 \mathrm{~min}$. However, the chlorination process introduces the risk of the generation of disinfection by-products [48]. More than $80 \%$ of E2 could be removed via the photo-Fenton process, however the additional step required for the removal of the reagents employed would increase the operational costs [49]. Zhang et al. [50] and Ohko et al. [16] demonstrated that photo-catalysis with $\mathrm{TiO}_{2}$ to be efficient in the elimination of E1 and E2. However, these approaches require significant contact times to achieve satisfactory removals. Ozonation has been reported as an efficient oxidation process for the removal of EDCs (>90\%), however the process can also generate toxic products [51,52]. Plasma can be an alternative process which can be used for removal of pollutants. The advantage of plasma over ozone is that, plasma contains over 100 reactive species in humid air (including ozone), many of which are more active. Gao et al. [30] achieved 100\% removal of E2 using a DBD plasma reactor, however an increase in concentration to $900 \mu \mathrm{g} / \mathrm{L}$ reduced the removal to $64 \%$ after 30 min of plasma treatment. In another study, a synergetic system which combined a DBD plasma discharge and Pt-TiO2 achieved $99.8 \%$ efficiency with $72 \%$ achieved with the DBD reactor alone for a treatment time of $30 \mathrm{~min}$ and an initial concentration of $400 \mu \mathrm{g} / \mathrm{L}$ [31]. Furthermore, a 96\% degradation of BPA, at an initial concentration of $1 \mathrm{mg} / \mathrm{L}$, was found for a DBD reactor using helium as the carrier gas [32].

The removal efficiency may be characterised by the amount of EDC degraded per unit of energy (yield). The energy yield depends on the type of discharge reactor, initial concentration and nature of the compound [40]. The energy yield of EDC degradation was calculated and the results were shown in Fig. 5. With increasing 

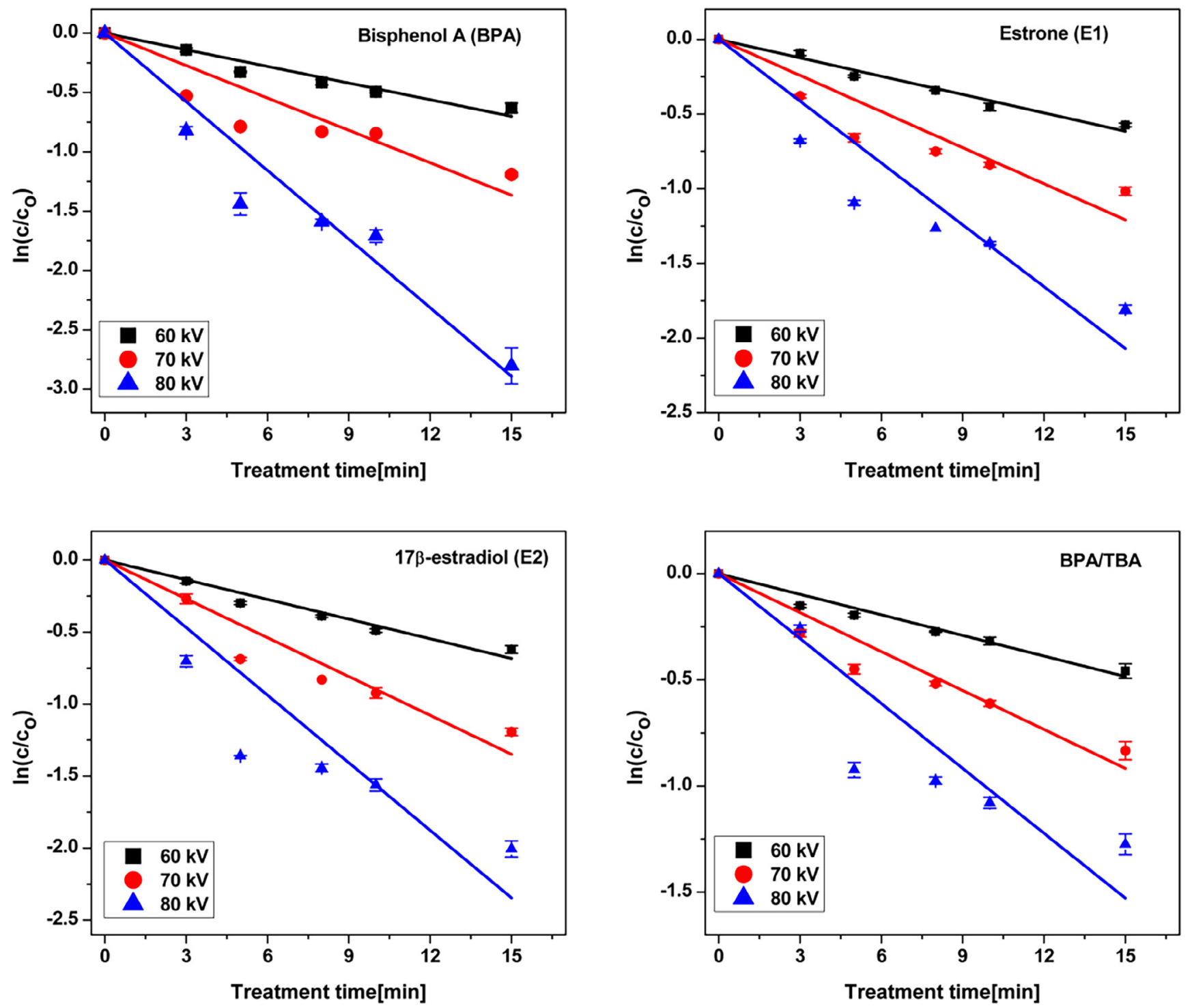

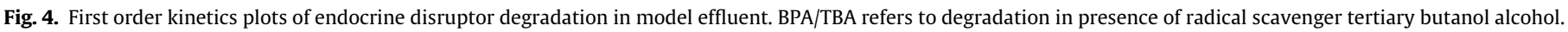

Table 1

Model parameters for endocrine degradation based on first-order kinetics.

\begin{tabular}{llll}
\hline Endocrine disruptor & Voltage $(\mathrm{kV})$ & Rate constant $k\left(\mathrm{~min}^{-1}\right)$ & $\mathrm{R}^{2}(\mathrm{Adj})$ \\
\hline Bisphenol A (BPA) & 60 & $0.045 \pm 0.003$ & 0.97 \\
& 70 & $0.086 \pm 0.011$ & 0.93 \\
& 80 & $0.189 \pm 0.016$ & 0.97 \\
Estrone (E1) & 60 & $0.041 \pm 0.002$ & 0.98 \\
& 70 & $0.076 \pm 0.009$ & 0.93 \\
& 80 & $0.132 \pm 0.014$ & 0.95 \\
$17 \beta$-Estradiol (E2) & 60 & $0.044 \pm 0.003$ & 0.98 \\
& 70 & $0.087 \pm 0.086$ & 0.96 \\
Bisphenol with TBA & 60 & $0.149 \pm 0.02$ & 0.93 \\
& 70 & $0.031 \pm 0.012$ & 0.99 \\
& 80 & $0.059 \pm 0.005$ & 0.97 \\
\hline
\end{tabular}

Note: BPA/TBA refers to degradation in presence of radical scavenger tertiary butanol alcohol.

applied voltage from $60 \mathrm{kV}$ to $70 \mathrm{kV}$, the energy yield decreased from $1295 \times 10^{-6}$ to $1249 \times 10^{-6} \mathrm{~g} / \mathrm{kW}$ h for BPA, $777 \times 10^{-6}$ to $737 \times 10^{-6} \mathrm{~g} / \mathrm{kW}$ h for E1, $1006 \times 10^{-6}$ to $810 \times 10^{-6} \mathrm{~g} / \mathrm{kW}$ h for
E2 and $805 \times 10^{-6}$ to $652 \times 10^{-6} \mathrm{~g} / \mathrm{kW}$ h for BPA/TBA, respectively. Comparing with previous studies on EDC degradation using DBD reactors $[30,31]$ our design was found to have slightly low energy yield values. This might be due to a high initial concentration of the solution, the volume of samples treated and the presence of competing organic matter as reactive sinks. The degradation of diuron in aqueous solution by DBD plasma, by Feng et al. [53], reported high energy yield values of $0.16 \mathrm{~g} / \mathrm{kW}$ h. Similarly, Reddy et al. [40] also reported a high energy yield values of $0.298 \mathrm{~g} / \mathrm{kW}$ h for the mineralization of endosulfan in an aqueous medium by DBD plasma. AOP technologies which employ chemical addition are typically high energy consumption and environmentally hazardous [41]. For example, Jantawasu et al. [54] obtained a 78\% decomposition of methyl orange by nanocrystalline mesoporous-assembled TiO2 photocatalysis, after a $4 \mathrm{~h}$ treatment. The energy cost and treatment time were rather high when compared to non-thermal plasma. As compared to other common AOPs, such as $\mathrm{UV} / \mathrm{H}_{2} \mathrm{O}_{2}$ and ozone $/ \mathrm{H}_{2} \mathrm{O}_{2}$ the primary benefit of DBD plasma is the ability to generate UV light and oxidizing species, ozone, hydroxyl radicals, etc. without chemical addition or the use of UV lamp [41]. 
Table 2

Removal efficiencies of estrogens using different oxidative technologies.

\begin{tabular}{|c|c|c|c|c|c|}
\hline Process & $\begin{array}{l}\text { Estrogens } \\
\text { studied }\end{array}$ & $\begin{array}{l}\text { Removal } \\
(\%)\end{array}$ & Treatment conditions & Other observations & Reference \\
\hline Chlorination & E1 & 70 & $1.0 \mathrm{mg} / \mathrm{L}$ contact time of $15 \mathrm{~min}$ & Matrix used was water with buffer solution & {$[48]$} \\
\hline Photo-Fenton & $\mathrm{E} 2$ & $\begin{array}{l}86.4 \\
98\end{array}$ & $\begin{array}{l}\mathrm{pH}-7.47 \alpha-\mathrm{FeOOH}-(5 \mathrm{~g} / \mathrm{L})-8 \mathrm{~h} \\
\mathrm{pH}-3.07 \alpha-\mathrm{FeOOH}-(5 \mathrm{~g} / \mathrm{L})-8 \mathrm{~h}\end{array}$ & $\begin{array}{l}\text { Matrix used was Milli-Q water at initial concentration } \\
\text { of } 272 \mu \mathrm{g} / \mathrm{L}\end{array}$ & [49] \\
\hline $\mathrm{TiO}_{2} / \mathrm{UV}$ & $\begin{array}{l}\text { E1, E2 } \\
\text { E2 }\end{array}$ & $\begin{array}{l}94 \\
99\end{array}$ & $\begin{array}{l}1 \mathrm{~g} / \mathrm{L} \mathrm{TiO} 2 \text { and } 1 \mathrm{~h} \\
1 \mathrm{~g} / \mathrm{L} \mathrm{TiO} 2 \text { and } 30 \mathrm{~min}\end{array}$ & Matrix used was deionized water & $\begin{array}{l}{[50]} \\
{[16]}\end{array}$ \\
\hline Ozonation & $\begin{array}{l}\text { E2, E1, } \\
\text { EE2 } \\
\text { BPA }\end{array}$ & 10094100 & $\begin{array}{l}0.38 \mathrm{mg} / \mathrm{min} 4 \mathrm{~min}(1.52 \mathrm{mg} / \mathrm{L}) .0 .38 \mathrm{mg} / \mathrm{min}- \\
8 \mathrm{~min}(3.04 \mathrm{mg} / \mathrm{L}) . \text { Aqueous } \mathrm{O}_{3}(15-400 \mu \mathrm{M}) \\
\text { treatment for } 24 \mathrm{~h}\end{array}$ & $\begin{array}{l}\text { Matrix used was water at initial concentration of } \\
10 \mathrm{mg} / \mathrm{L}, \mathrm{pH}-9 . \text { Matrix used was Milli-Q water with } \\
\text { initial concentration of } 100 \mu \mathrm{M} \text { and } \mathrm{pH}-6.5\end{array}$ & {$[52][51]$} \\
\hline $\begin{array}{l}\text { Combination of } \\
\mathrm{AOP}\left(\mathrm{US} / \mathrm{O}_{3}\right)\end{array}$ & BPA & $\begin{array}{l}34.6 \\
63 \\
100\end{array}$ & $\begin{array}{l}\text { US intensity of } 60 \mathrm{~W} / \mathrm{cm}^{2} \\
\mathrm{O}_{3} \text { flow rate of } 10 \mathrm{~mL} / \mathrm{min} \\
\mathrm{US} / \mathrm{O}_{3} \text { at } 60 \mathrm{~W} / \mathrm{cm}^{2} \text { followed by } \mathrm{O}_{3} \text { treatment at } \\
\text { flow rate of } 10 \mathrm{~mL} / \mathrm{min}\end{array}$ & $\begin{array}{l}\text { Matrix used was deionized water at initial concetration } \\
\text { of } 100 \mathrm{ug} / \mathrm{L}\end{array}$ & [82] \\
\hline DBD plasma & E2 & $\begin{array}{l}100 \\
75 \\
64 \\
64\end{array}$ & $\begin{array}{l}\text { Peak voltage of } 12 \mathrm{kV} \text { at } \mathrm{pH}-5.6-30 \text { min of } \\
\text { treatment with ambient air as discharge gas }\end{array}$ & $\begin{array}{l}100 \mathrm{ug} / \mathrm{L} \\
300 \mathrm{ug} / \mathrm{L} \\
600 \mathrm{ug} / \mathrm{L} \\
900 \mathrm{ug} / \mathrm{L} \\
\text { Matrix used was ultrapure water }\end{array}$ & {$[30]$} \\
\hline $\begin{array}{l}\text { DBD plasma } \\
\text { combined with } \\
\text { Pt- } \mathrm{TiO}_{2} \\
\text { photocatalyst }\end{array}$ & E2 & $\begin{array}{l}75 \\
90 \\
99.8\end{array}$ & $\begin{array}{l}\text { DBD plasma alone } \\
\mathrm{DBD}+\mathrm{TiO}_{2} \\
\mathrm{DBD}+\mathrm{Pt}_{-} \mathrm{TiO}_{2} \\
\text { Peak voltage of } 12 \mathrm{kV}-30 \text { min of treatment with } \\
\text { ambient air as discharge gas }\end{array}$ & Matrix used was ultrapure water at $\mathrm{pH}-5.6$ & {$[31]$} \\
\hline $\begin{array}{l}\text { Gliding arc plasma } \\
\text { with ferrous } \\
\text { ions }\end{array}$ & BPA & $\begin{array}{l}100 \\
70\end{array}$ & $\begin{array}{l}\text { COD } \\
\text { TOC } \\
\text { At voltage of } 10 \mathrm{kV}-30 \text { min of treatment. Under } \\
\text { different working gases such as air, argon, } \\
\text { oxygen/argon mixture }(20 / 80, \mathrm{v} / \mathrm{v})\end{array}$ & $\begin{array}{l}\text { Matrix used was acidified osmosis water at pH-3 with } \\
\text { initial concentration of } 120 \mu \mathrm{M}(28 \mathrm{mg} / \mathrm{L})\end{array}$ & [33] \\
\hline DBD plasma & BPA & 96 & $\begin{array}{l}\text { Voltage of } 20 \mathrm{kV} \text { treatment time of } 5 \mathrm{~min} \text { with } \\
\text { helium as discharge gas }\end{array}$ & Initial concetration of $1 \mathrm{mg} / \mathrm{L}$ & {$[32]$} \\
\hline
\end{tabular}

\subsection{The role of active species}

The plasma discharge was characterized using optical emission spectroscopy (OES). From Fig. 6, it can be seen that small peaks of - $\mathrm{OH}$ were recorded at 295-300 nm. Emissions from $\mathrm{N}_{2}$ and excited species of $\mathrm{N}_{2}^{+}$exhibited distinct peaks in the UV region [55]. A highintensity metastable singlet oxygen $(\mathrm{O})$ was recorded at around 750 and $780 \mathrm{~nm}$ which is similar to reported studies for DBDs operating at atmospheric pressures in air [56]. As expected the atmospheric discharge is an effective source of reactive nitrogen and oxygen species (RNOS). Plasma species such as superoxides, hydroxyl radicals, and peroxynitrites are short lived whereas, hydrogen peroxide is relatively more stable even up to $24 \mathrm{~h}$. Such active species play an important role in the degradation of EDC's. Ozone is a widely applied strong oxidizing agent for the treatment of wastewater. Misra et al. [20] reported that ozone is one the most stable active species generated in DBD with a high oxidation potential of $2.02 \mathrm{~V}$. The ozone reaction with EDCs takes place through molecular and radical reactions. The ozone concentrations measured after $10 \mathrm{~min}$ of plasma treatment were found to be 1600 , 2400 and $3100 \mathrm{ppm}$ (within $\pm 10 \%$ errors) for applied voltages of 60,70 , and $80 \mathrm{kV}$ respectively. The mechanism of ozone degradation of contaminants can be either by direct oxidation or an indirect one, by converting into hydroxyl radicals. The direct reaction is predominant in acidic environments while at high $\mathrm{pH}$ indirect oxidation takes place. However, both reactions can occur simultaneously and ozone may react with unsaturated functional groups present in organic molecules. Electron dissociation of water molecules leads to the formation of $\cdot \mathrm{OH}$ which further forms $\mathrm{H}_{2} \mathrm{O}_{2}$ in both air and water.

In order to study the function of hydroxyl radicals $(\cdot \mathrm{OH})$ during DBD plasma treatment tertiary butanol $(4 \% \mathrm{v} / \mathrm{v})$, a hydroxyl radical scavenger was added to the BPA solution with the degradation efficiency reported as a function of treatment time and applied voltage (see Fig. 4). The data shows that the process efficiency was reduced by $\sim 20 \%$ with the addition. Similar observations were reported by Gao et al. [30] and Mehrvar et al. [57]. The addition of the radical scavenger also resulted in a decrease in the rate constant from $0.189 \mathrm{~min}^{-1}$ to $0.098 \mathrm{~min}^{-1}$ at $80 \mathrm{kV}$. The results infer that tertiary butanol competes with BPA to consume the generated hydroxyl radicals and can restrain the interaction between $\mathrm{OH}$ and the BPA molecule.

Fig. 7(a) shows the TOC removal efficiencies of all three EDC's as a function of treatment time. The initial concentration of EDC spiked dairy effluent corresponds to TOC concentrations of $1125.44,1245.9$ and $1243.7 \mathrm{mg} / \mathrm{L}$ for BPA, E1 and E2 respectively. As shown, the TOC removal efficiencies of all three EDC's, linearly increased with time, reaching a maximum removal of $21.5 \%$, $17.8 \%$ and $22.3 \%$ for BPA, E1 and E2 respectively, after 15 min of plasma treated at $80 \mathrm{kV}$. Interestingly, all the tested EDCs were effectively degraded more than $80 \%$ within 15 min however, the TOC removal efficiencies achieved were not more than $30 \%$, which can be attributed to the formation of low-molecular weight compounds such as oxalic acid and formic acid before being completely mineralized [58].

Fig 7(b) shows the evolution of $\mathrm{pH}$ as a function of treatment time and applied voltage for the treated samples, with $\mathrm{pH}$ values changing from 6.95 to 5.41 . The decrease in $\mathrm{pH}$ values is due to the formation of nitric acid, nitrous acids and intermediate organic acids (oxalic and formic acid) that originate from the nitrogen in the air and the degraded EDCs. It was known that these organic acids have large acidic dissociation constants, which lead to significant reductions in solution $\mathrm{pH}$ [29]. The conductivity of the model effluent with EDCs is shown in Fig. 7(c). It was observed that the conductivity increased with increases in treatment time and applied voltage due to the generation of ionic species. The conductivity of the control sample was $750 \mu \mathrm{S} / \mathrm{cm}$, which increased to $1660 \mu \mathrm{S} / \mathrm{cm}$ after plasma treatment for $15 \mathrm{~min}$ at $80 \mathrm{kV}$. An increase in the conductivity of brewery effluent and dye solution with plasma treatment was demonstrated by previous authors 

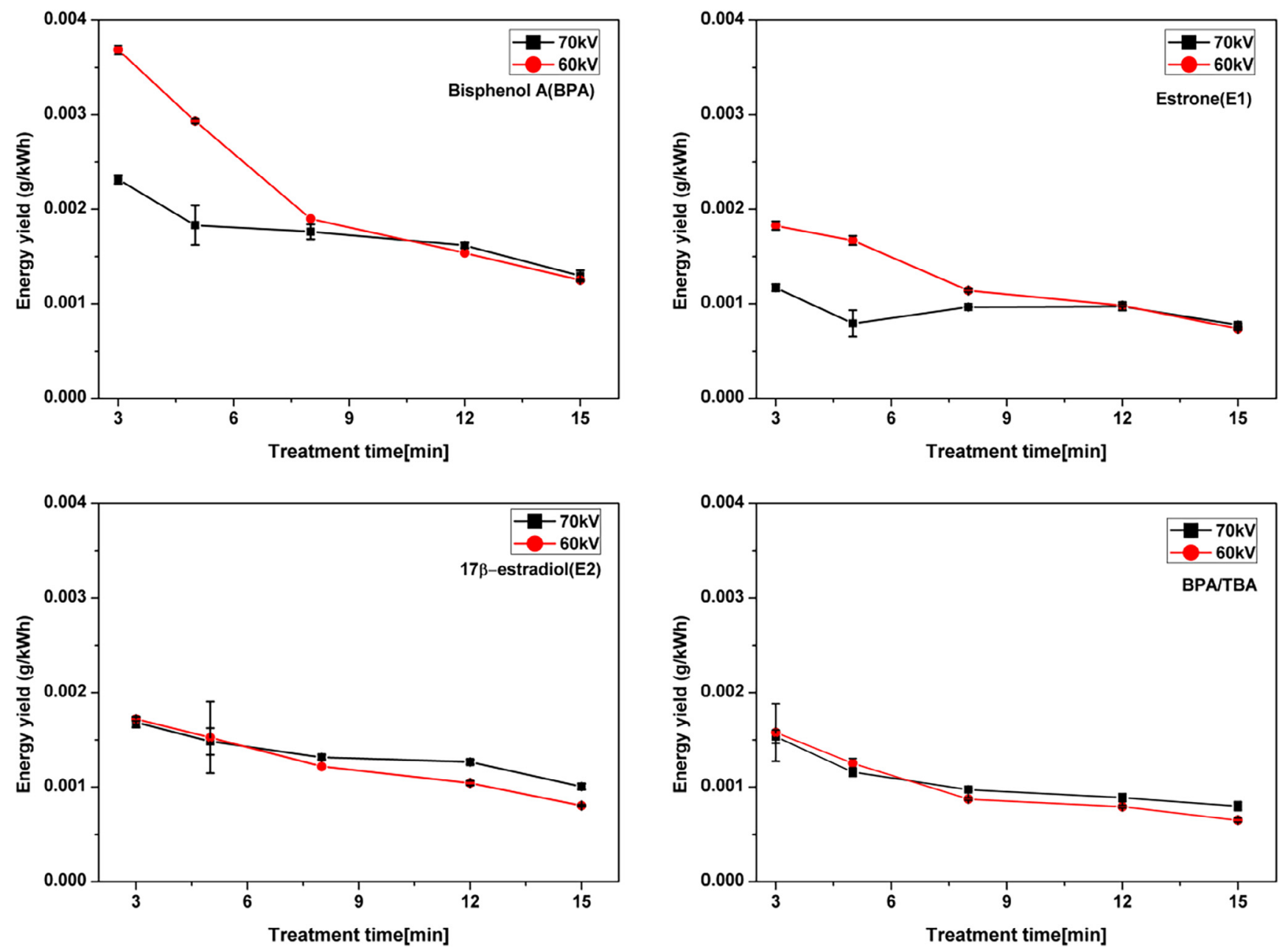

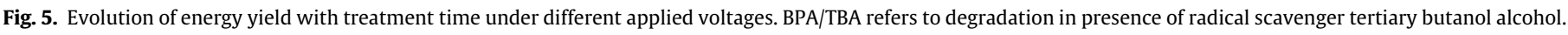

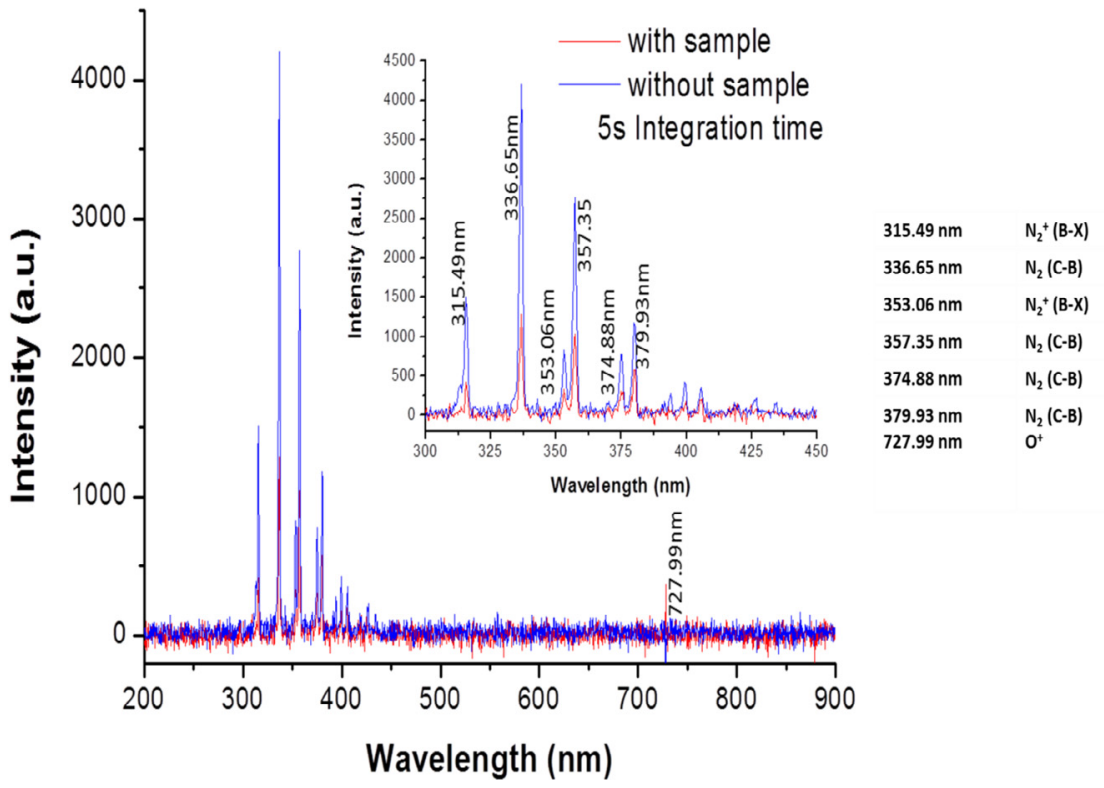

Fig. 6. Typical Optical Emission Spectrum (OES) of the dielectric barrier discharge in air. Operating voltage $80 \mathrm{kV}$.

$[59,60]$. The increased ionic strength will reduce ozone solubility in the bulk solution because of the salting-out effect, which would also likely affect the degree of oxidation. The dissolution of nitrite and nitrate in water which are inevitably produced by electric dis- 

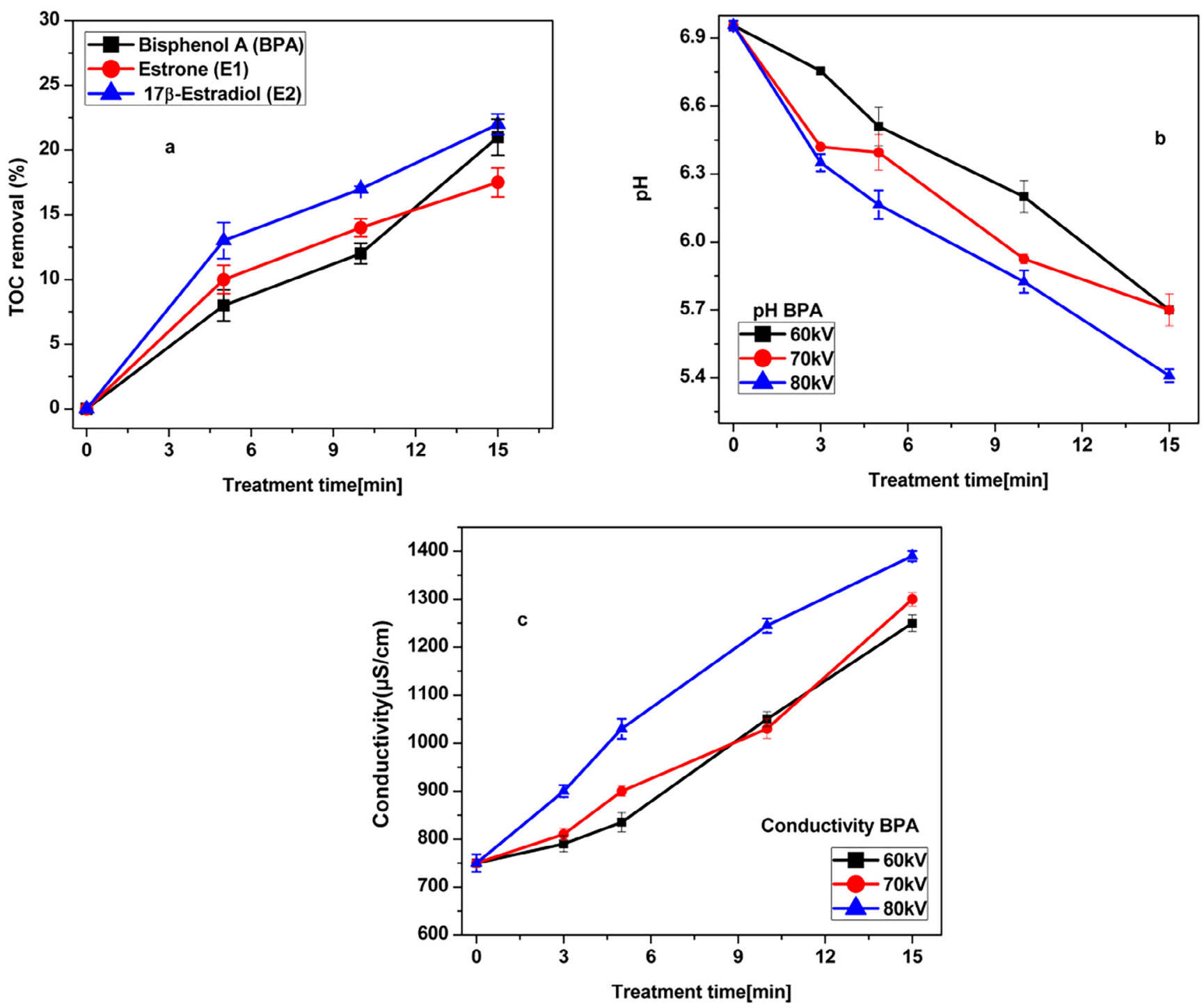

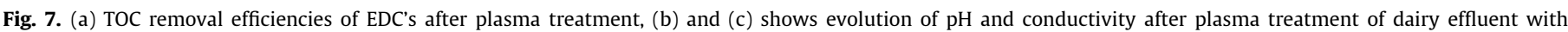
Bisphenol A.

charges can also induce significant changes in the $\mathrm{pH}$ and electrical conductivity of the effluent. The dissolution of nitrite to form nitric acid can be explained as follows.

$N_{2}+e^{-} \rightarrow 2 N^{\cdot}+e^{-}$

$\mathrm{O}_{2}+e^{-} \rightarrow 20^{\cdot}+e^{-}$

$N^{\cdot}+\mathrm{O} \rightarrow \mathrm{NO}_{2}$

$\mathrm{NO}+\mathrm{O} \rightarrow \mathrm{NO}_{2}$

$\mathrm{NO}_{2}+\mathrm{OH} \rightarrow \mathrm{HNO}_{3}$

Nitrate and Nitrite concentrations were measured in the model effluent sample, without the presence of EDCs to ensure no interaction from their presence with the reagents used. Nitrite can be formed not only by the degradation of the effluent but also by the electrical discharge in air. Fig. 8(a) and (b) shows the temporal variations of nitrite and nitrate concentrations in the plasma treated dairy effluent. The concentrations of nitrite and nitrate after $15 \mathrm{~min}$ treatment were found to be $56.50,57.62,66.86 \mathrm{mg} / \mathrm{L}$ and $114.87,146.30,163.59 \mathrm{mg} / \mathrm{L}$ for applied voltages of 60,70 , and $80 \mathrm{kV}$ respectively. These values are substantially lower than the maximum permissible concentration (MPC) for nitrates or nitrites in dairy effluents [61]. The formation of nitrite and nitric acid can be explained from Eqs. (3)-(11), where formation of nitrate is attributed to the dissociation of nitric acid formed by the sequence of reactions [62].

$\mathrm{NO}+\mathrm{OH} \rightarrow \mathrm{HNO}_{2}$

$\mathrm{HNO}_{2}+\mathrm{H}_{2} \mathrm{O} \leftrightarrow \mathrm{NO}_{2}^{-}+\mathrm{H}_{3} \mathrm{O}^{+}$

$\mathrm{NO}_{2}^{-}+\mathrm{H}_{2} \mathrm{O}_{2}+\mathrm{H}_{3} \mathrm{O}^{+} \rightarrow \mathrm{ONOOH}+2 \mathrm{H}_{2} \mathrm{O}$

$\mathrm{ONOOH} \rightarrow \mathrm{HNO}_{3}$

It was also known that nitrate is formed from nitrite oxidation and also an intermediate. The transient character of nitrite ions was observed previously $[63,64]$. About $30 \%$ of nitrites were converted to nitrates after $24 \mathrm{~h}$ of storage in the tank contacting with air [65].

The concentration of hydrogen peroxide $\left(\mathrm{H}_{2} \mathrm{O}_{2}\right)$ is presented in Fig. 8(c), the concentrations of $\mathrm{H}_{2} \mathrm{O}_{2}$ increased linearly with respect to time for all voltages with concentrations in the range of 2074$16810 \mathrm{mg} / \mathrm{L}$. The high amounts of $\mathrm{H}_{2} \mathrm{O}_{2}$ in the treated effluent are due to the retention of reactive species in the gas phase in contact 

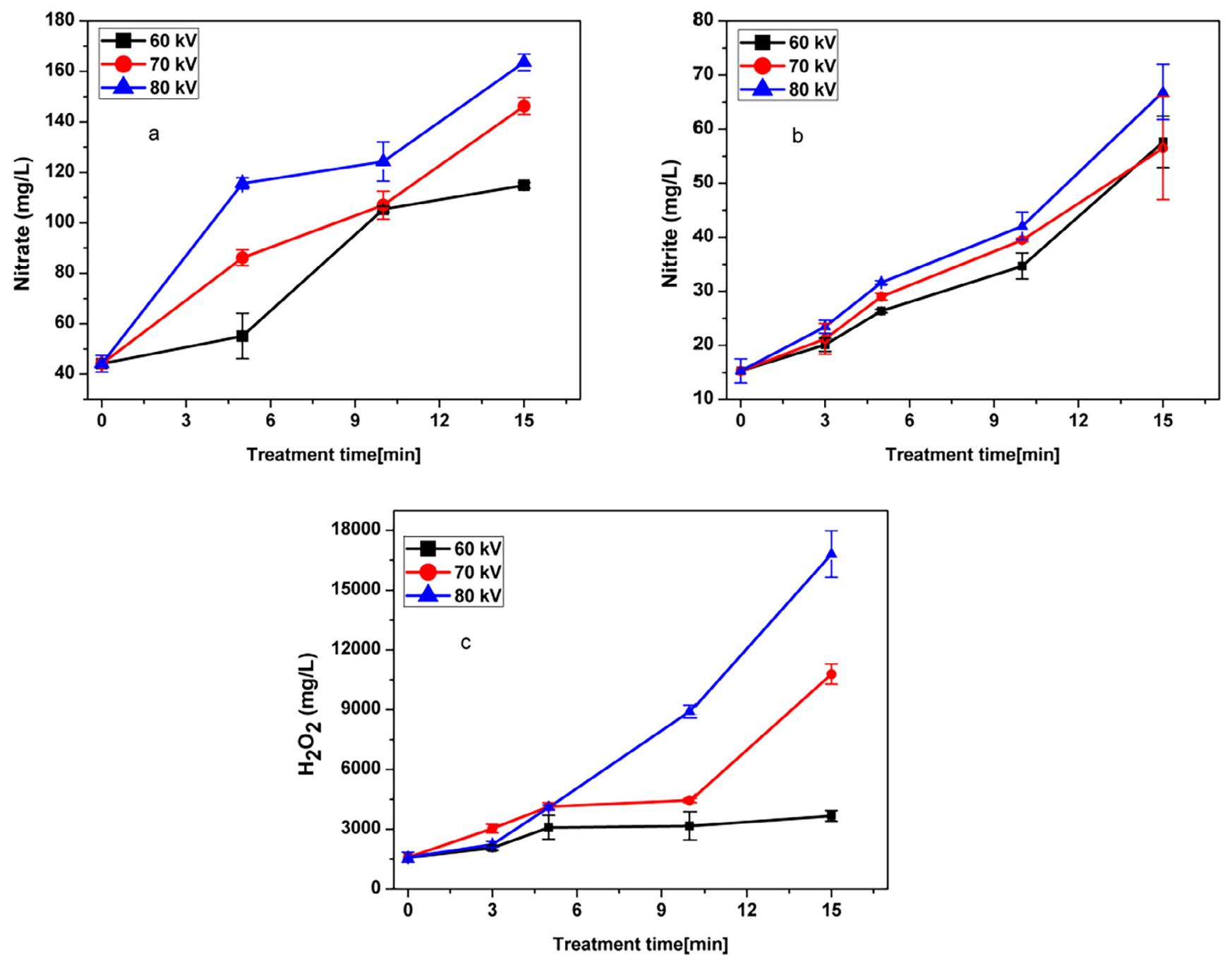

Fig. 8. Variation of nitrite, nitrate and $\mathrm{H}_{2} \mathrm{O}_{2}$ concentration in plasma treated dairy effluent.

with the treated liquid for extended periods of time. Earlier work by our group achieved stable concentrations of $\mathrm{H}_{2} \mathrm{O}_{2}$ in PBS solutions for extended storage times of several weeks in a closed reactor [39].

The concentrations of formic and oxalic acid in the dairy effluent were determined by ion chromatography and the results are presented in Fig. 9. The concentrations of oxalic acid measured after $15 \mathrm{~min}$ treatment were found to be 200.09, 231.31 and $242.42 \mathrm{mg} / \mathrm{L}$ for applied voltages of 60,70 , and $80 \mathrm{kV}$ respectively. As shown in Fig. 9, the concentration of both organic acids increased with treatment time and all applied voltages. Interestingly, for all the organic acids measured oxalic acid was found to be the most abundant in the treated effluent. It was also observed that the initial formation of formic acid was rapid, however after $10 \mathrm{~min}$, the concentration was found to decrease. This phenomenon is attributed to mineralization of organic acids. The decrease in pH presented in Fig. 7(b) also, explains the formation of organic acids as byproducts. Similar results in the formation of organic acid as by-products has been demonstrated by Kim et al. [58] in plasma-treated aqueous antibiotic solutions.

\subsection{Degradation mechanism of endocrine disruptors}

The intermediate products were identified using UHPLC-MS in both the positive and negative modes. It has been reported that the negative ion mode is preferred for the identification of target estrogens [66]. In this study, the maximum concentrations of EDCs were spiked to identify the intermediate products (see Supplementary material Tables S1 and S2). The MS spectrum (see Supplementary Fig. S4) of Bisphenol A showed a deprotonated major molecular ion at $m / z 227$ and a minor ion at $m / z 134$ and the fragmentation spectra showed peaks at $\mathrm{m} / z 213$ and $\mathrm{m} / \mathrm{z} 93$ which were similar to the published reports of Debrode et al. [51]. The intermediate product ions are identified at $\mathrm{m} / \mathrm{z} 243, \mathrm{~m} / \mathrm{z} 260, \mathrm{~m} / \mathrm{z}$ $275, m / z 221$. It was observed that the peak area of the product ion $m / z 227$ decreased with plasma exposure time. Conversely, an increase in the peak area of other products was seen in the $60 \mathrm{kV}$ sample. Major peaks at $\mathrm{m} / z 275$ and $\mathrm{m} / \mathrm{z} 319$ were also observed. These might be 3-nitro-bisphenol $A$ and 3,3'-dinitrobisphenol A, the nitrite compounds formed by reactive nitrogen species [33,67]. The fragments ions at $m / z 243, \mathrm{~m} / z 149$ and $m / z 134$ could result in ring opening. These might be due to hydroxylation of BPA via direct reaction between plasma active species such as ozone and hydroxyl radicals. The formation of monohydroxy BPA was further confirmed by fragmented peak ions at $m / z 228$ and $m / z 93$. The reaction further proceeded to yield dihydroxy BPA $m / z 261$. The peak identified in the MS spectra at $\mathrm{m} / \mathrm{z}$ of 241 is an intermediate product, likely to be diketone, formed by the selective reaction of ozone with an electron rich site. The loss in a carbonyl group would lead to another peak at $m / z 213$ 

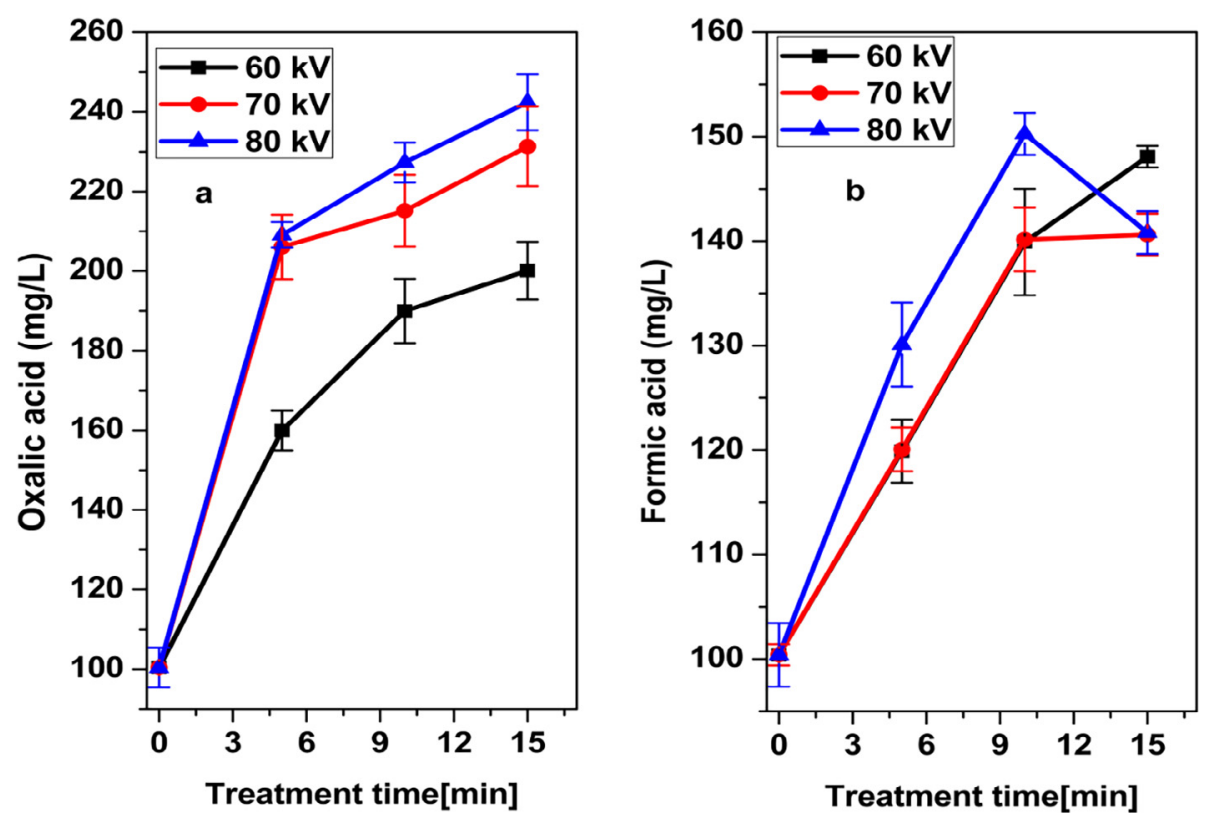

Fig. 9. Variation of organic acid concentrations produced during degradation of plasma treated dairy effluent.

[M-H] $]^{-}$. However, the peak at $m / z 276.10$ would correspond to dicarboxylic acid formed by initial attack of .OH via hydrogen abstraction. Other peaks identified in the MS spectrum were observed at $\mathrm{m} / \mathrm{z} 219$ and $\mathrm{m} / \mathrm{z} 235$. Similar degradation products were detected in ozonation of bisphenol A by Debrode et al. [51] and Tay et al. [68]. Additional peaks at $m / z 232[\mathrm{M}-\mathrm{H}]^{-}$and $m / z$ $189[\mathrm{M}-\mathrm{H}]^{-}$with a loss of $\mathrm{CO}_{2}$ were also evident. The fragments at $m / z 149,136,134,110$ could result from a chain fragmentation of BPA. Based on previous reports $[69,70]$ the fragments at $m / z$ 110 are intermediates of catechol, orthoquinone and hydroquinone. The reaction of ozone and hydroxyl radicals with the phenol ring of BPA results in similar reaction by-products of phenol. These products were identified with samples treated for $70 \mathrm{kV}$ for $5 \mathrm{~min}$. A large number of peaks observed in the chromatograms are polar compounds such as acid and aldehydes. In the present study, oxalic and formic acid were identified which, is similar to the findings by Garoma et al. [71].

The degraded products and intermediates of E1 and E2 are identified from the MS spectrum. It is known that E1 and E2 differ by two mass units, with molecular weights of $270.16 \mathrm{~g} / \mathrm{mol}$ for E1 and $272.18 \mathrm{~g} / \mathrm{mol}$ for E2. The structural difference is due to the presence of a ketone group in position 17 of E1 and a hydroxyl group in the same position of the E2 molecule [8]. As mentioned plasma species target high electron rich cites such as the ortho and para position of EDCs to form hydroxylated derivatives. The deprotonated ion at $\mathrm{m} / \mathrm{z} 285$ and $\mathrm{m} / \mathrm{z} 287$ were identified as 2-hydroxy estrone and 2-hydroxyestradiol (2OH-E2) or 6-hydroxyestradiol (6OH-E2). These products were also identified for ozonation [14,72], photo-Fenton reaction [73] and photo degradation [74] of E2. In addition to the major fragments at $m / z 287$ other peaks at $m / z 259,183,158,134$ were also identified in the MS spectrum of E2. The oxidation of E2 by reactive species will yield diketone $\mathrm{E} 2$ and the initial attack of $\cdot \mathrm{OH}$ via hydrogen abstraction leads to opening of the aromatic ring which is converted to dicarboxylic acids. This was confirmed by the major peak at $m / z 319$ and other ions at $m / z 262,162,135$. The MS spectra shows a peaks at $m / z 303,287,259,175$ and $m / z 287,259,162$, 134 these compounds represent the 2-hydroxyestradiol or its resonance structure 10e-17b-dihydroxy-1,4-estradien-3-one (DEO) [16]. A fragment ion peak $m / z 259[\mathrm{M}-\mathrm{H}]^{-}$was observed in the
MS spectra formed by the elimination of the carbonyl group from compound $\mathrm{m} / \mathrm{z} 288$ and consecutive elimination of carbonyl and oxygen at $m / z 303$. As previously reported by Gao et al. [30] a number of other intermediates at $\mathrm{m} / \mathrm{z} 336, \mathrm{~m} / \mathrm{z} 352, \mathrm{~m} / \mathrm{z} 368$ with molecular weights greater than E2 are also observed in the spectrum. In addition to the peak at $m / z$ 368, a few other fragments at $\mathrm{m} / z, 336,292$ and 274 were also observed. In addition to the fragment ion peak $m / z 368$, the product ion at $m / z 352$ is identified as the deprotonated molecule $\left([\mathrm{M}-\mathrm{H}]^{-}\right.$with other fragment ions $336,319,292$ and 274. Similar fragments as $m / z 319,292,275$ were also seen for the deprotonated molecule at $m / z 336$. The fragments ion at peak $m / z 319$ is formed by the loss of oxygen, where $m / z 291$ $[\mathrm{M}-\mathrm{H}]^{-}$might be formed by the loss of the carboxyl group and $\mathrm{m} / \mathrm{z}$ $275[\mathrm{M}-\mathrm{H}]^{-}$could be attributed to the consecutive loss of $\mathrm{CO}_{2}$ and $\mathrm{H}_{2} \mathrm{O}$. The loss of $\mathrm{H}_{2} \mathrm{O}$ from the ion at $m / z 352[\mathrm{M}-\mathrm{H}]^{-}$and loss of $\mathrm{O}_{2}$ from ion $m / z 368[\mathrm{M}-\mathrm{H}]^{-}$would yield the ion $m / z$ 336. These results are similar to previous studies $[8,30,75,76]$. Another peak was identified at $m / z 317$ (2-nitro $17 \beta$-estradiol), this compound might be an intermediate formed by the reaction of nitrogen species. Besides, these a few other peak ions at $m / z 208,131$, and 90 were also identified. These peaks would be chain fragmented products of E2 which result in further oxidation to oxalic acid and formic acid.

Based on the intermediates formed possible degradation pathways for the tested EDC's are proposed. The pathway for BPA (I) to (II) can occur through hydroxylation or reaction between BPA and ozone and hydroxyl radicals as shown in Fig. 10 pathway 1. A similar reaction for E1(I) to (II)) and E2(P) to (P1) is also proposed for the degradation pathway of E1 and E2 see Fig. 11(a) and (b). The most probable attack of plasma active species is against one of the ortho positions (with respect to phenolic hydroxyl group) of the aromatic ring of E1 and E2. The most probable site for the initial addition of the $\mathrm{OH}$ radical is at the $\mathrm{C} 2$ atom leading to the formation of 2-hydroxy estrone (II) and 2-hydroxyestradiol (2OH-E2) (P1) or 6-hydroxyestradiol $(6 \mathrm{OH}-\mathrm{E} 2)[30,75]$. It is reported that the estrogenic activity of hydroxylated EDCs is much lower than that of the parent compound [72,77]. The degraded products such as hydroxylated EDCs are further attacked by $\cdot \mathrm{OH}$ radicals on the aromatic ring. The increase in the addition of hydroxylated structures involves ring opening, leading to oxidized products to form 


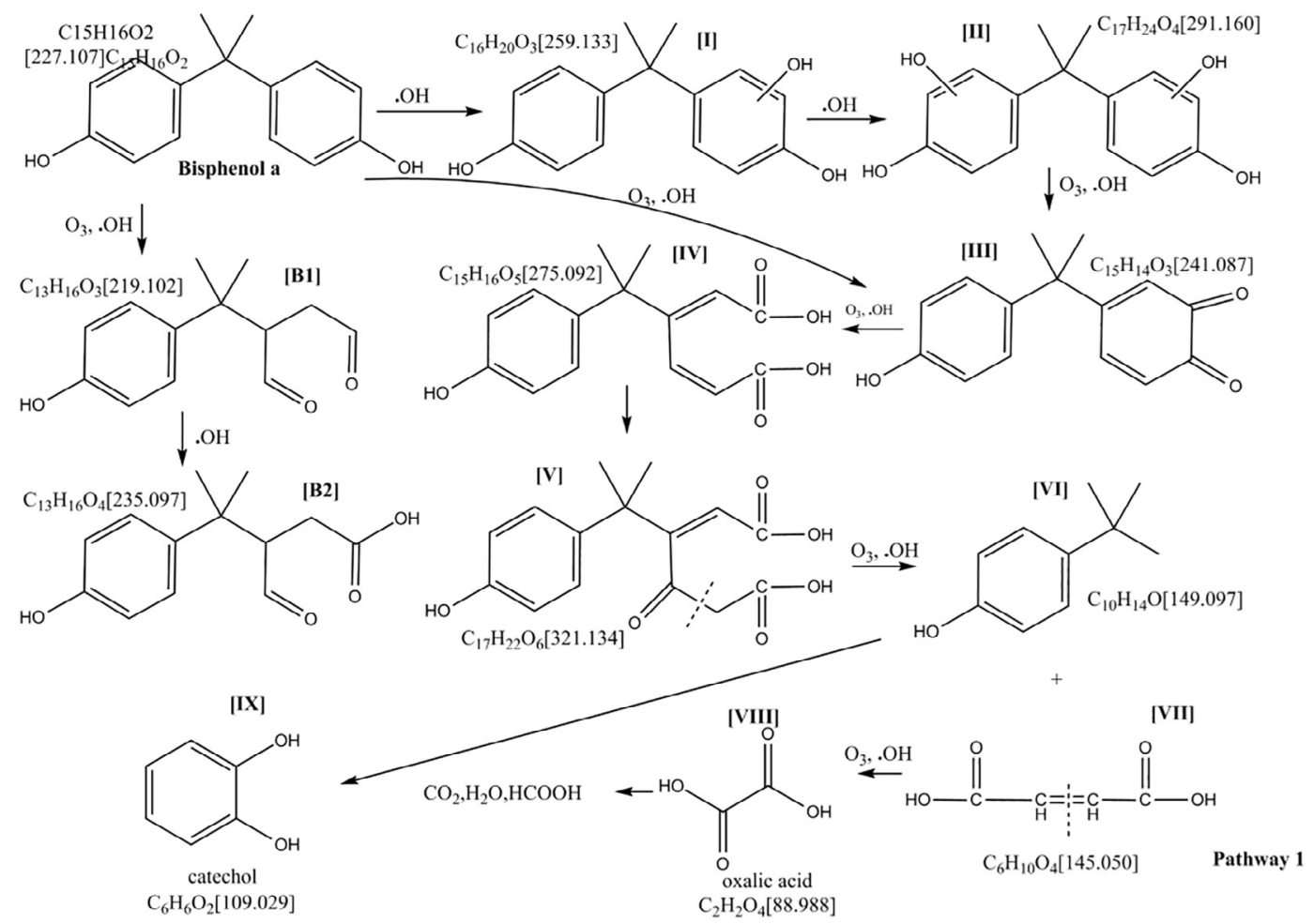

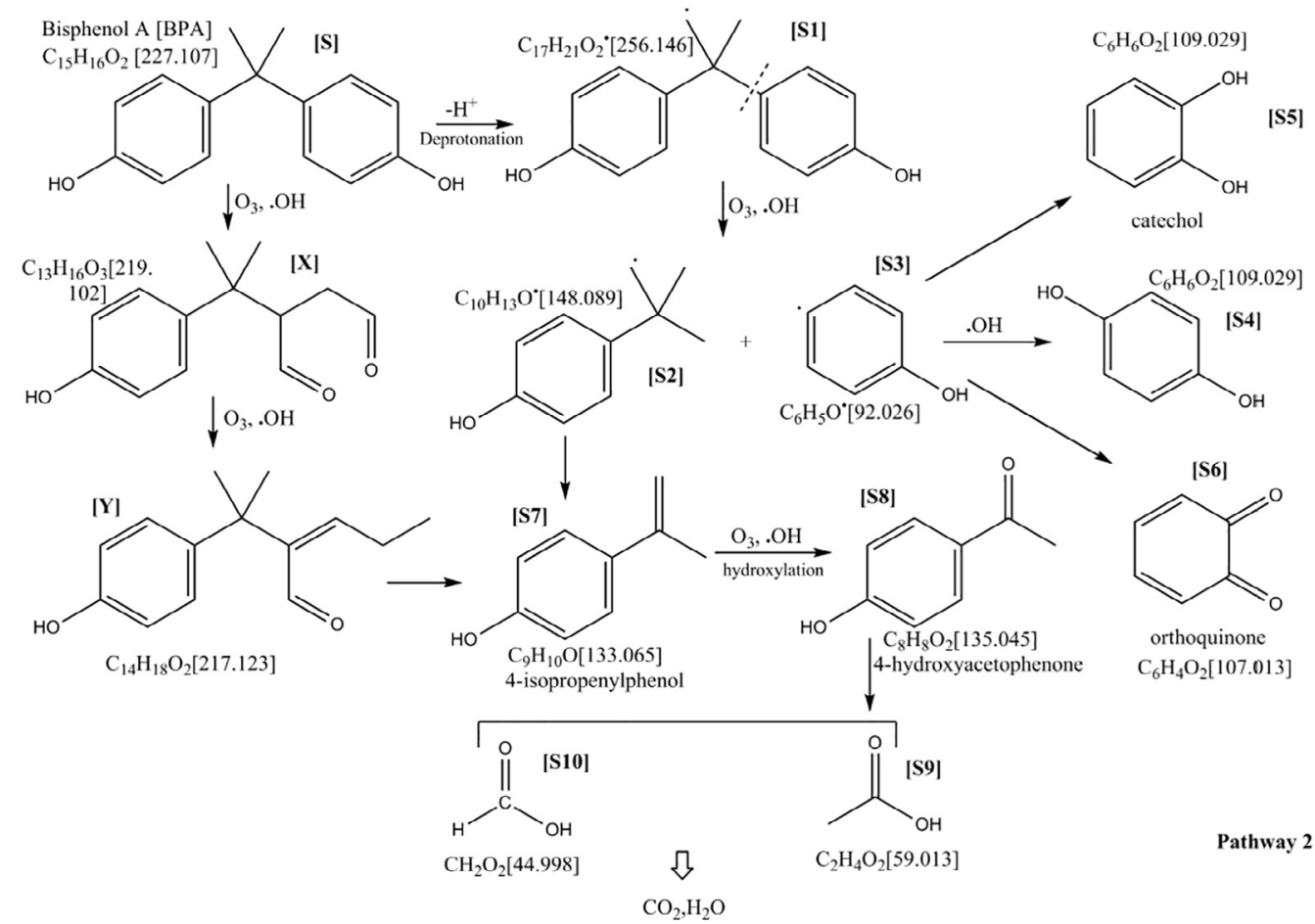

Fig. 10. The proposed degradation pathways of Bisphenol A (BPA) with chemical formula and monoisotopic mass of identified products.

diketone intermediates (II) to (III) and (P1) to (P2) which convert to dicarboxylic acids (III) to (IV) and (P2) to (P3) to (P4). These dicarboxylic acids further oxidize to smaller products. The reaction (IV) to (V) and (P4) to (P5) to (P6) is formed either by direct reaction of ozone or indirect oxidation by hydroxyl radicals. Degradation of these EDCs by plasma is initiated with the phenol-moiety oxidation [16]. Thus, this involves oxidation reactions to form a resonance structure P7 (DEO) with a low estrogenic activity and which is favored by an attack by $\cdot \mathrm{OH}$ and $\cdot \mathrm{OOH}$ radicals [16,78]. The deprotonation of the BPA molecule or reaction with plasma reactive species at electron rich sites by ${ }^{\circ} \mathrm{OH}$ abstraction at the side chains leads to the formation of S1 compound (Fig. 10 pathway 2). The reaction is proceeded by cleavage of the $\mathrm{C}-\mathrm{C}$ bond resulting in S2 and phenol radicals (S3) [68]. Moreover the phenol radical reacts with $\mathrm{OH}$ to form hydroquinone (S4) or catechol (S5) and further orthoquinone (S6) which has relatively weak estrogenic activ- 


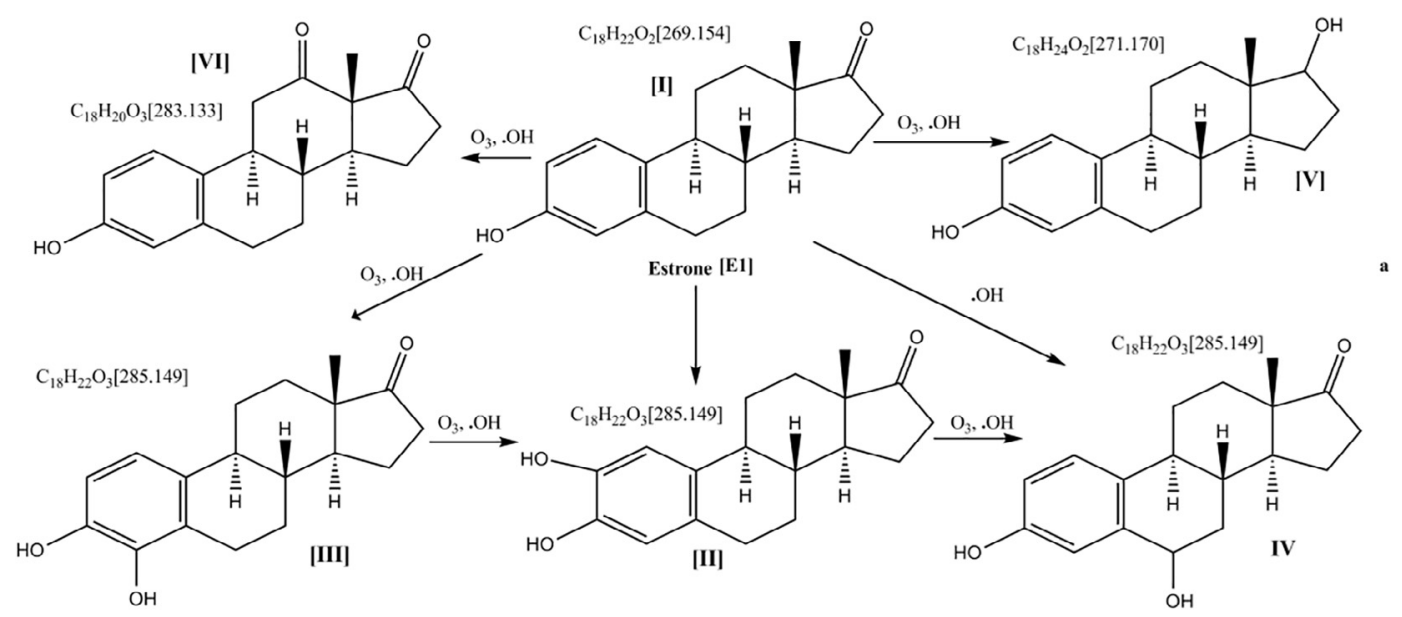

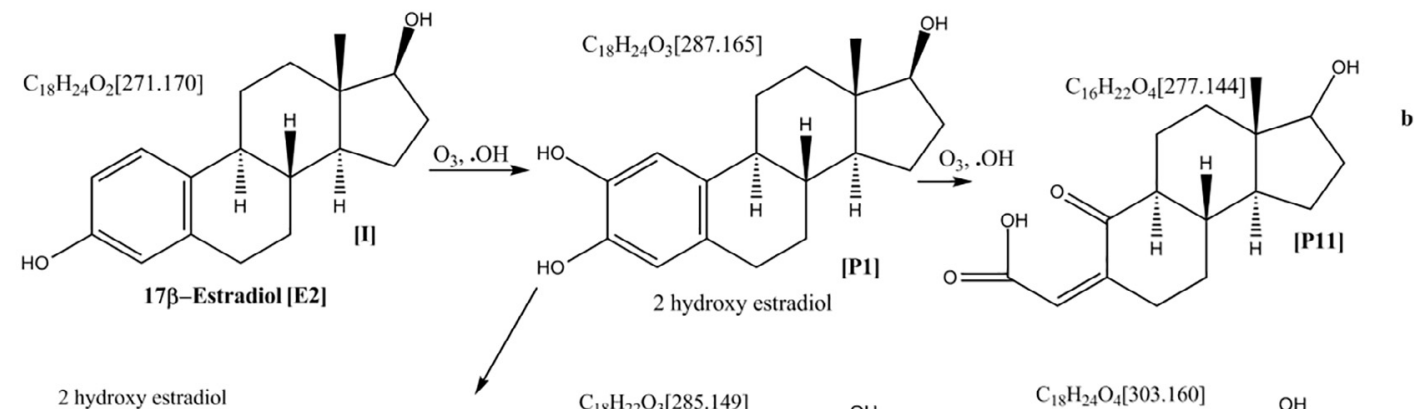

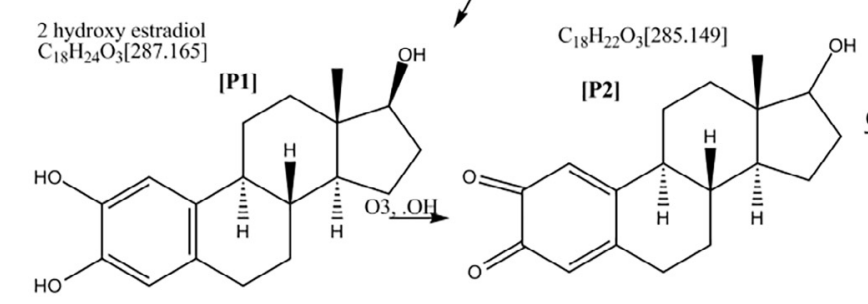

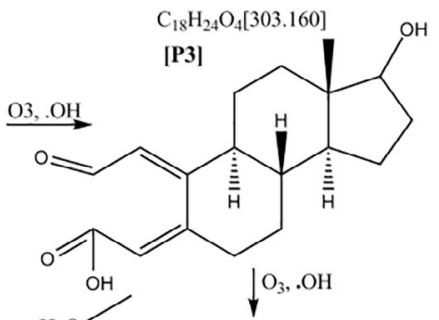

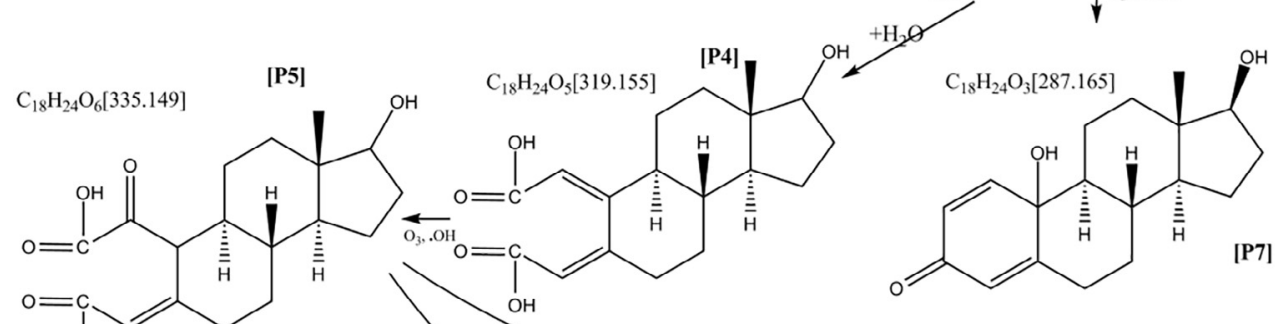

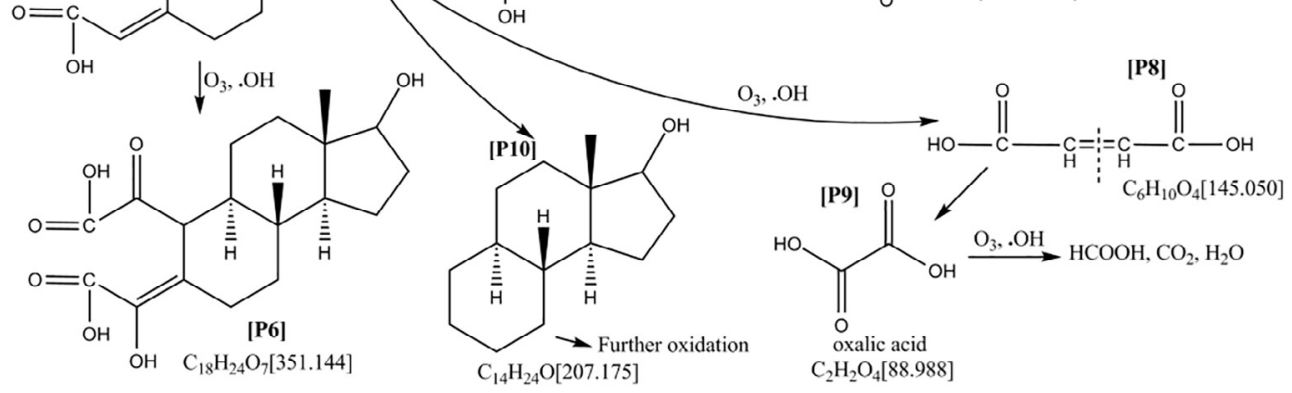

Fig. 11. The proposed degradation pathways of estrone (a) and $17 \beta$-estradiol (b) with chemical formula and monoisotopic mass of identified products.

ity compared with BPA $[79,80]$. The intermediate product (S2) undergoes both direct and indirect reaction with ozone and hydroxyl radicals to form 4-isopropenylphenol (S7) and 4hydroxyacetophenone (S8). However, these compounds are similar to products identified by Ike et al. [81] which showed a lower estrogenic activity compared to BPA. The results obtained in this study suggest that atmospheric air plasma technology could be applied for the removal of hazardous chemicals from processing effluents, with efficient degradation pathways that mitigate the formation of biologically active intermediates.

\section{Conclusion}

This study demonstrates that atmospheric air plasma can effectively degrade endocrine disruptors in a model dairy effluent. The removal efficiency achieved at $80 \mathrm{kV}$ for $15 \mathrm{~min}$ was found to be 
$>80 \%$ for all EDCs tested. The degradation kinetics followed a firstorder kinetic model. The rate constants were found to increase with voltage and treatment time. The plasma discharge under atmospheric air conditions was monitored using optical emission spectroscopy and metastables measured using $\mathrm{H}_{2} \mathrm{O}_{2}$, nitrates or nitrite assays. The addition of tertiary butanol reduced the removal efficiency by $20 \%$ which reveals the major role of ' $\mathrm{OH}$ in the degradation process. The oxidative decomposition of EDCs by plasma species leads to intermediate products which were identified by UHPLC-MS and LC-MS. Based on the intermediates formed a degradation mechanism was proposed for all three EDCs. The use of ecofriendly gasses and fast removal rates make this technology a potential approach for industrial application. This work provides an efficient method for degradation of contaminants in water and has the potential to lead to novel applications for environmental protection.

\section{Acknowledgements}

The authors would like to acknowledge funding from the Food Institutional Research Measure administered by the Department of Agriculture, Food \& the Marine, Ireland (Grant number: 13F442).

\section{Appendix A. Supplementary data}

Supplementary data associated with this article can be found, in the online version, at http://dx.doi.org/10.1016/j.cej.2017.05.178.

\section{References}

[1] W. Zheng, Y. Zou, X. Li, M.L. Machesky, Fate of estrogen conjugate $17 \alpha$ estradiol-3-sulfate in dairy wastewater: comparison of aerobic and anaerobic degradation and metabolite formation, J. Hazard. Mater. 258 (2013) 109-115.

[2] E. Wielogórska, C. Elliott, M. Danaher, O. Chevallier, L. Connolly, Validation of an ultra high performance liquid chromatography-tandem mass spectrometry method for detection and quantitation of 19 endocrine disruptors in milk, Food Control 48 (2015) 48-55.

[3] S. Hartmann, M. Lacorn, H. Steinhart, Natural occurrence of steroid hormones in food, Food Chem. 62 (1998) 7-20.

[4] D.R. Raman, E.L. Williams, A.C. Layton, R.T. Burns, J.P. Easter, A.S. Daugherty, M D. Mullen, G.S. Sayler, Estrogen content of dairy and swine wastes, Environ. Sci Technol. 38 (2004) 3567-3573.

[5] S.D. Kim, J. Cho, I.S. Kim, B.J. Vanderford, S.A. Snyder, Occurrence and removal of pharmaceuticals and endocrine disruptors in South Korean surface, drinking, and waste waters, Water Res. 41 (2007) 1013-1021.

[6] M. Petrovic, E. Eljarrat, M.L. De Alda, D. Barceló, Endocrine disrupting compounds and other emerging contaminants in the environment: a survey on new monitoring strategies and occurrence data, Anal. Bioanal. Chem. 378 (2004) 549-562.

[7] T. Colborn, F.S. vom Saal, A.M. Soto, Developmental effects of endocrinedisrupting chemicals in wildlife and humans, Environ. Health Perspect. 101 (1993) 378

[8] R.O. Pereira, C. Postigo, M.L. de Alda, L.A. Daniel, D. Barceló, Removal of estrogens through water disinfection processes and formation of by-products, Chemosphere 82 (2011) 789-799.

[9] E.L. Gregoraszczuk, A. Rak, G. Ludewig, A. Gasińska, Effects of estradiol, PCB3, and their hydroxylated metabolites on proliferation, cell cycle, and apoptosis of human breast cancer cells, Environ. Toxicol. Pharmacol. 25 (2008) 227-233.

[10] L.J. Mills, C. Chichester, Review of evidence: are endocrine-disrupting chemicals in the aquatic environment impacting fish populations?, Sci Total Environ. 343 (2005) 1-34.

[11] P.A. Swathanthra, V.B. Rao, Removal of chromium FROM aqueous solution using low cost adsorbents,, in: Chemical and Bioprocess Engineering: Trends and Developments, Apple Academic Press, 2015, pp. 321-329.

[12] S.A. Snyder, P. Westerhoff, Y. Yoon, D.L. Sedlak, Pharmaceuticals, personal care products, and endocrine disruptors in water: implications for the water industry, Environ. Eng. Sci. 20 (2003) 449-469.

[13] J. Hu, S. Cheng, T. Aizawa, Y. Terao, S. Kunikane, Products of aqueous chlorination of $17 \beta$-estradiol and their estrogenic activities, Environ. Sci. Technol. 37 (2003) 5665-5670.

[14] S. Irmak, O. Erbatur, A. Akgerman, Degradation of $17 \beta$-estradiol and bisphenol $\mathrm{A}$ in aqueous medium by using ozone and ozone/UV techniques, J. Hazard. Mater. 126 (2005) 54-62.

[15] E.J. Rosenfeldt, P.J. Chen, S. Kullman, K.G. Linden, Destruction of estrogenic activity in water using UV advanced oxidation, Sci. Total Environ. 377 (2007) 105-113.
[16] Y. Ohko, K.-I. Iuchi, C. Niwa, T. Tatsuma, T. Nakashima, T. Iguchi, Y. Kubota, A. Fujishima, $17 \beta$-Estradiol degradation by TiO2 photocatalysis as a means of reducing estrogenic activity, Environ. Sci. Technol. 36 (2002) 4175-4181.

[17] B. Jiang, J. Zheng, S. Qiu, M. Wu, Q. Zhang, Z. Yan, Q. Xue, Review on electrical discharge plasma technology for wastewater remediation, Chem. Eng. J. 236 (2014) 348-368.

[18] C. Sarangapani, Y. Devi, R. Thirundas, U.S. Annapure, R.R. Deshmukh, Effect of low-pressure plasma on physico-chemical properties of parboiled rice, LWTFood Sci. Technol. (2015)

[19] R. Thirumdas, C. Sarangapani, U. Annapure, Cold plasma: a novel non-thermal technology for food processing, Food Biophys. 10 (2015) 1-11.

[20] N.N. Misra, D. Ziuzina, P.J. Cullen, K.M. Keener, Characterization of a novel atmospheric air cold plasma system for treatment of packaged biomaterials, Trans. ASABE 56 (2013) 1011-1016.

[21] N. Misra, B. Tiwari, K. Raghavarao, P.J. Cullen, Nonthermal plasma inactivation of food-borne pathogens, Food Eng. Rev. 3 (2011) 159-170.

[22] J. Foster, B.S. Sommers, S.N. Gucker, I.M. Blankson, G. Adamovsky, Perspectives on the interaction of plasmas with liquid water for water purification, IEEE Trans. Plasma Sci. 40 (2012) 1311-1323.

[23] N.N. Misra, K.M. Keener, P. Bourke, P.J. Cullen, Generation of in-package cold plasma and efficacy assessment using methylene blue, Plasma Chem. Plasma Process. (2015) 1-14.

[24] N. Misra, S.K. Pankaj, T. Walsh, F. O’Regan, P. Bourke, P.J. Cullen, In-package nonthermal plasma degradation of pesticides on fresh produce, J. Hazard. Mater. 271 (2014) 33-40.

[25] C. Sarangapani, N. Misra, V. Milosavljevic, P. Bourke, F. O’Regan, P. Cullen, Pesticide degradation in water using atmospheric air cold plasma, J. Water Process Eng. 9 (2016) 225-232.

[26] Y. Devi, R. Thirumdas, C. Sarangapani, R. Deshmukh, U. Annapure, Influence of cold plasma on fungal growth and aflatoxins production on groundnuts, Food Control 77 (2017) 187-191.

[27] A.A. Assadi, A. Bouzaza, S. Merabet, D. Wolbert, Modeling and simulation of VOCs removal by nonthermal plasma discharge with photocatalysis in a continuous reactor: synergetic effect and mass transfer, Chem. Eng. J. 258 (2014) 119-127.

[28] G. Maxime, A.A. Amine, B. Abdelkrim, W. Dominique, Removal of gas-phase ammonia and hydrogen sulfide using photocatalysis, nonthermal plasma, and combined plasma and photocatalysis at pilot scale, Environ. Sci. Pollut. Res. 21 (2014) 13127-13137.

[29] K.-S. Kim, C.-S. Yang, Y. Mok, Degradation of veterinary antibiotics by dielectric barrier discharge plasma, Chem. Eng. J. 219 (2013) 19-27.

[30] L. Gao, L. Sun, S. Wan, Z. Yu, M. Li, Degradation kinetics and mechanism of emerging contaminants in water by dielectric barrier discharge non-thermal plasma: the case of 17ß-Estradiol, Chem. Eng. J. 228 (2013) 790-798.

[31] Y. Chen, L. Sun, Z. Yu, L. Wang, G. Xiang, S. Wan, Synergistic degradation performance and mechanism of $17 \beta$-estradiol by dielectric barrier discharge non-thermal plasma combined with Pt-TiO2, Sep. Purif. Technol. 152 (2015) $46-54$.

[32] M. Hijosa-Valsero, R. Molina, J.M. Bayona, Assessment of a dielectric barrier discharge plasma reactor at atmospheric pressure for the removal of bisphenol A and tributyltin, Environ. Technol. 35 (2014) 1418-1426.

[33] F. Abdelmalek, R. Torres, E. Combet, C. Petrier, C. Pulgarin, A. Addou, Gliding arc discharge (GAD) assisted catalytic degradation of bisphenol A in solution with ferrous ions, Sep. Purif. Technol. 63 (2008) 30-37.

[34] Y.-H. Yu, M. Jun, Y.-J. Hou, Degradation of 2, 4-dichlorophenoxyacetic acid in water by ozone-hydrogen peroxide process, J. Environ. Sci. 18 (2006) 10431049.

[35] S. Tchamango, C.P. Nanseu-Njiki, E. Ngameni, D. Hadjiev, A. Darchen, Treatment of dairy effluents by electrocoagulation using aluminium electrodes, Sci. Total Environ. 408 (2010) 947-952.

[36] C. Sarangapani, Y. Dixit, V. Milosavljevic, P. Bourke, C. Sullivan, P. Cullen, Optimization of atmospheric air plasma for degradation of organic dyes in wastewater, Water Sci. Technol. (2016).

[37] D. Giustarini, R. Rossi, A. Milzani, I. Dalle-Donne, Nitrite and nitrate measurement by Griess reagent in human plasma: evaluation of interferences and standardization, Methods Enzymol. 440 (2008) 361-380.

[38] P. Lu, D. Boehm, P. Bourke, P.J. Cullen, Achieving reactive species specificity within plasma-activated water through selective generation using air spark and glow discharges, Plasma Processes Polym. (2017).

[39] D. Boehm, C. Heslin, P.J. Cullen, P. Bourke, Cytotoxic and mutagenic potential of solutions exposed to cold atmospheric plasma, Sci. Rep. 6 (2016).

[40] P. Manoj, Kumar Reddy, S. Mahammadunnisa, C. Subrahmanyam, Catalytic non-thermal plasma reactor for mineralization of endosulfan in aqueous medium: a green approach for the treatment of pesticide contaminated water, Chem. Eng. J. 238 (2014) 157-163.

[41] B. Jiang, J. Zheng, Q. Liu, M. Wu, Degradation of azo dye using non-thermal plasma advanced oxidation process in a circulatory airtight reactor system, Chem. Eng. J. 204-206 (2012) 32-39.

[42] B.P. Dojčinović, G.M. Roglić, B.M. Obradović, M.M. Kuraica, M.M. Kostić, J. Nešić, D.D. Manojlović, Decolorization of reactive textile dyes using water falling film dielectric barrier discharge, J. Hazard. Mater. 192 (2011) 763-771.

[43] N. Misra, S. Patil, T. Moiseev, P. Bourke, J. Mosnier, K. Keener, P. Cullen, Inpackage atmospheric pressure cold plasma treatment of strawberries, J. Food Eng. 125 (2014) 131-138.

[44] U. Von Gunten, Ozonation of drinking water: Part I Oxidation kinetics and product formation, Water Res. 37 (2003) 1443-1467. 
[45] Y. Bai, J. Chen, Y. Yang, L. Guo, C. Zhang, Degradation of organophosphorus pesticide induced by oxygen plasma: effects of operating parameters and reaction mechanisms, Chemosphere 81 (2010) 408-414.

[46] Y. Bai, J. Chen, H. Mu, C. Zhang, B. Li, Reduction of dichlorvos and omethoate residues by 02 plasma treatment, J. Agric. Food Chem. 57 (2009) 6238-6245.

[47] G.R. Boyd, J.M. Palmeri, S. Zhang, D.A. Grimm, Pharmaceuticals and personal care products (PPCPs) and endocrine disrupting chemicals (EDCs) in stormwater canals and Bayou St John in New Orleans, Louisiana, USA, Sci. Total Environ. 333 (2004) 137-148.

[48] H. Nakamura, R. Kuruto-Niwa, M. Uchida, Y. Terao, Formation of chlorinated estrones via hypochlorous disinfection of wastewater effluent containing estrone, Chemosphere 66 (2007) 1441-1448.

[49] Z. Yaping, H. Jiangyong, Photo-Fenton degradation of $17 \beta$-estradiol in presence of $\alpha$-FeOOHR and H 2 O 2, Appl. Catal. B 78 (2008) 250-258.

[50] Y. Zhang, J. Zhou, B. Ning, Photodegradation of estrone and $17 \beta$-estradiol in water, Water Res. 41 (2007) 19-26.

[51] M. Deborde, S. Rabouan, P. Mazellier, J.-P. Duguet, B. Legube, Oxidation of bisphenol A by ozone in aqueous solution, Water Res. 42 (2008) 4299-4308.

[52] Y. Lin, Z. Peng, X. Zhang, Ozonation of estrone, estradiol, diethylstilbestrol in waters, Desalination 249 (2009) 235-240.

[53] J. Feng, Z. Zheng, Y. Sun, J. Luan, Z. Wang, L. Wang, J. Feng, Degradation of diuron in aqueous solution by dielectric barrier discharge, J. Hazard. Mater. 154 (2008) 1081-1089.

[54] P. Jantawasu, T. Sreethawong, S. Chavadej, Photocatalytic activity of nanocrystalline mesoporous-assembled TiO 2 photocatalyst for degradation of methyl orange monoazo dye in aqueous wastewater, Chem. Eng. J. 155 (2009) 223-233.

[55] M. Heise, T. Lierfeld, O. Franken, W. Neff, Single filament charge transfer and UV-emission properties of a cascaded dielectric barrier discharge (CDBD) setup, Plasma Sources Sci. Technol. 13 (2004) 351.

[56] R.W.B. Pearse, A.G. Gaydon, R.W.B. Pearse, A.G. Gaydon, The identification of molecular spectra, Chapman and Hall London, 1976.

[57] M. Mehrvar, W.A. Anderson, M. Moo-Young, Photocatalytic degradation of aqueous organic solvents in the presence of hydroxyl radical scavengers, Int. J. Photoenergy 3 (2001) 187-191.

[58] K.-S. Kim, S.K. Kam, Y.S. Mok, Elucidation of the degradation pathways of sulfonamide antibiotics in a dielectric barrier discharge plasma system, Chem. Eng. J. 271 (2015) 31-42.

[59] A. Doubla, S. Laminsi, S. Nzali, E. Njoyim, J. Kamsu-Kom, J.-L. Brisset, Organic pollutants abatement and biodecontamination of brewery effluents by a nonthermal quenched plasma at atmospheric pressure, Chemosphere 69 (2007) $332-337$.

[60] R. Zhang, C. Zhang, X. Cheng, L. Wang, Y. Wu, Z. Guan, Kinetics of decolorization of azo dye by bipolar pulsed barrier discharge in a threephase discharge plasma reactor, J. Hazard. Mater. 142 (2007) 105-110.

[61] B.S. Shete, N. Shinkar, Dairy industry wastewater sources, characteristics \& its effects on environment, Int. J. Current Eng. Technol. 3 (2013) 1611-1615.

[62] B.M. Cadorin, V.D. Tralli, E. Ceriani, L.O. de Brito Benetoli, E. Marotta, C. Ceretta, N.A. Debacher, C. Paradisi, Treatment of methyl orange by nitrogen nonthermal plasma in a corona reactor: The role of reactive nitrogen species, J. Hazard. Mater. 300 (2015) 754-764.

[63] Y. Shen, L. Lei, X. Zhang, M. Zhou, Y. Zhang, Effect of various gases and chemical catalysts on phenol degradation pathways by pulsed electrical discharges, J. Hazard. Mater. 150 (2008) 713-722.

[64] J.-L. Brisset, E. Hnatiuc, Peroxynitrite: a re-examination of the chemical properties of non-thermal discharges burning in air over aqueous solutions, Plasma Chem. Plasma Process. 32 (2012) 655-674.
65] I. Kornev, G. Osokin, A. Galanov, N. Yavorovskiy, S. Preis, Formation of nitriteand nitrate-ions in aqueous solutions treated with pulsed electric discharges, Ozone Sci. Eng. 35 (2013) 22-30.

[66] S. Bourcier, C. Poisson, Y. Souissi, S. Kinani, S. Bouchonnet, M. Sablier Elucidation of the decomposition pathways of protonated and deprotonated estrone ions: application to the identification of photolysis products, Rapid Commun. Mass Spectrom. 24 (2010) 2999-3010.

[67] S. Masuda, Y. Terashima, A. Sano, R. Kuruto, Y. Sugiyama, K. Shimoi, K. Tanji, H. Yoshioka, Y. Terao, N. Kinae, Changes in the mutagenic and estrogenic activities of bisphenol A upon treatment with nitrite, Mut. Res./Genet. Toxicol. Environ. Mutagen. 585 (2005) 137-146.

[68] K.S. Tay, N.A. Rahman, M.R.B. Abas, Degradation of bisphenol A by ozonation: rate constants, influence of inorganic anions, and by-products, Maejo Int. J. Sci. Technol. 6 (2012).

[69] Y. Yamamoto, E. Niki, H. Shiokawa, Y. Kamiya, Ozonation of organic compounds. 2. Ozonation of phenol in water, J. Org. Chem. 44 (1979) $2137-$ 2142 .

[70] T. Yamamoto, A. Yasuhara, H. Shiraishi, O. Nakasugi, Bisphenol A in hazardous waste landfill leachates, Chemosphere 42 (2001) 415-418.

[71] T. Garoma, S. Matsumoto, Y. Wu, R. Klinger, Removal of bisphenol A and its reaction-intermediates from aqueous solution by ozonation, Ozone Sci. Eng. 32 (2010) 338-343.

[72] D. Bila, A.F. Montalvao, D.D.A. Azevedo, M. Dezotti, Estrogenic activity removal of $17 \beta$-estradiol by ozonation and identification of by-products, Chemosphere 69 (2007) 736-746.

[73] Y. Zhao, J. Hu, W. Jin, Transformation of oxidation products and reduction of estrogenic activity of $17 \beta$-estradiol by a heterogeneous photo-Fenton reaction, Environ. Sci. Technol. 42 (2008) 5277-5284.

[74] P. Mazellier, L. Méité, J. De Laat, Photodegradation of the steroid hormones $17 \beta$-estradiol (E2) and 17 $\alpha$-ethinylestradiol (EE2) in dilute aqueous solution, Chemosphere 73 (2008) 1216-1223.

[75] J. Mai, W. Sun, L. Xiong, Y. Liu, J. Ni, Titanium dioxide mediated photocatalytic degradation of $17 \beta$-estradiol in aqueous solution, Chemosphere 73 (2008) 600-606.

[76] R. de Oliveira Pereira, M.L. de Alda, J. Joglar, L.A. Daniel, D. Barceló Identification of new ozonation disinfection byproducts of $17 \beta$-estradiol and estrone in water, Chemosphere 84 (2011) 1535-1541.

[77] T. Hirooka, H. Nagase, K. Uchida, Y. Hiroshige, Y. Ehara, J.I. Nishikawa, T. Nishihara, K. Miyamoto, Z. Hirata, Biodegradation of bisphenol A and disappearance of its estrogenic activity by the green alga Chlorella fusca var. vacuolata, Environ. Toxicol. Chem. 24 (2005) 1896-1901.

[78] M.M. Ngundi, O.A. Sadik, T. Yamaguchi, S.-I. Suye, First comparative reaction mechanisms of $\beta$-estradiol and selected environmental hormones in a redox environment, Electrochem. Commun. 5 (2003) 61-67.

[79] S. Kitamura, T. Suzuki, S. Sanoh, R. Kohta, N. Jinno, K. Sugihara, S.I. Yoshihara, N. Fujimoto, H. Watanabe, S. Ohta, Comparative study of the endocrinedisrupting activity of bisphenol A and 19 related compounds, Toxicol. Sci. 84 (2005) 249-259.

[80] K. Okuda, T. Fukuuchi, M. Takiguchi, S.i. Yoshihara, Novel pathway of metabolic activation of bisphenol A-related compounds for estrogenic activity, Drug Metab. Dispos. 39 (2011) 1696-1703.

[81] M. Ike, M.Y. Chen, C.S. Jin, M. Fujita, Acute toxicity, mutagenicity, and estrogenicity of biodegradation products of bisphenol-A, Environ. Toxicol. 17 (2002) 457-461.

[82] Z. Guo, R. Feng, Ultrasonic irradiation-induced degradation of lowconcentration bisphenol A in aqueous solution, J. Hazard. Mater. 163 (2009) $855-860$. 